


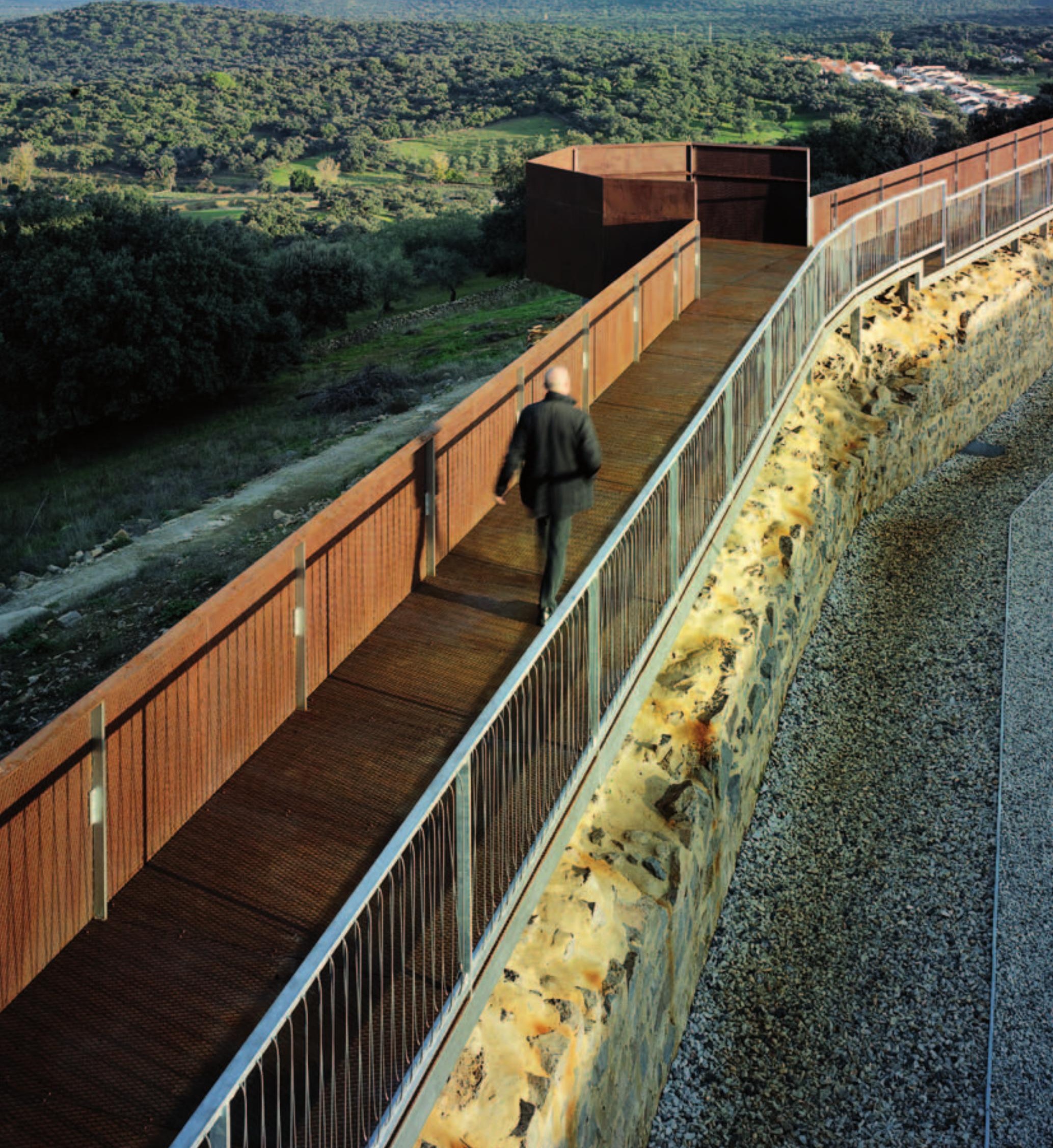




\section{Intervención en el castillo de Cala ¿2001-2011?: Ia transdisciplinariedad para un hacer arquitectónico patrimonial}

Rafael Herrera Limones,

estudio de arquitectura republica_dm:

R. Herrera + C. Parra + V. Rodríguez

+ M. López + Jc. Galindo

\section{Resumen}

El castillo de Cala es una de las fortificaciones medievales de la comarca serrana de Huelva; el estado inicial de ruina planteaba numerosos interrogantes sobre determinados aspectos constructivos y funcionales. La intervención pasa por la puesta en valor del conjunto monumental, mediante su recuperación volumétrico-espacial y la reparación de los daños, entendiendo que es un elemento patrimonial inserto en el "paisaje cultural" que, por lo tanto, debe ser tratado desde parámetros relativos a la actuación en éste. Para ello, se han tenido en cuenta criterios basados en la Carta de Cracovia de 2000, que no es sino una consecuencia de la multiplicidad de textos, estipulaciones y debates que, desde la Carta del Restauro, se han ido consensuando en el marco del panorama enormemente heterodoxo que supone cualquier pensamiento o acción en el campo arquitectónico del patrimonio.

En este contexto, el término "intervención" se habria de entender, en puridad, como proceso de pensamiento y actuación en aras de la re-habilitación para fines culturales y la re-cuperación social del BIC. Es decir: el estudio, la investigación, la discusión, el proceso iterativo... En resumen, el trabajo realizado por una multiplicidad de personas provenientes de diferentes disciplinas, junto con la final ejecución de unas labores constructivas, conducentes a la configuración formal de uno de los recintos amurallados de la banda gallega. Es ésta la visión cruzada que se pretende ofrecer en el presente artículo. De ahi, por ejemplo, las referencias a la "ficha técnica" al principio, como causa -no efecto- de la intervención arquitectónica, reflejando el proceso más desde la urdimbre transdisciplinar que desde una concepción piramidal y jerárquica. Todo ello en el marco de la situación económico-social de crisis...

\section{Palabras clave}

Arquitectura militar / Castillo de Cala (Huelva) / Conservación / Fortificaciones / Interdisciplinariedad / Intervención / Restauración / Valoración 


\section{PREÁMBULO}

A modo de digresión previa, es decir, no exactamente dentro del tema que debiéramos tratar, nos apetece -y a la vez nos resulta relevante- explicar cómo se articula este acercamiento gráfico y escrito al hecho arqueológico, histórico y arquitectónico (que constituye toda intervención en el patrimonio) y que, en este caso, por cuestiones sociales y ambientales, nos aprestamos a realizar.

Pues bien.

Querríamos, por esta vez, alejarnos de la explicación dogmática, en base a datos técnicos previos y resultados fotográficos finales.
No significa eso que este material referido (campañas arqueológicas, planimetría, memorias de proyecto, imágenes previas y finales...) no suponga la base real del presente artículo, ni que nos propongamos explicar una cuestión desarrollada en el tiempo por más de una década, exclusivamente desde el punto de vista literario. Ello resultaría seguramente en extremo árido y cuasi ininteligible.

Aunque, evidentemente, la dilatación en el tiempo del hecho arquitectónico no es exclusivo, ni mucho menos, del caso que nos ocupa, si suele resultar de especial relevancia en todas aquellas intervenciones relacionadas con el patrimonio, en las que, precisamente por las caracteristicas "temporales" de aquello en lo que se pretende intervenir, es el factor cronológico el que acaba sufriendo dilataciones extremas.

\section{intervención castillo cala / trans-disciplinariedad / ficha técnica}
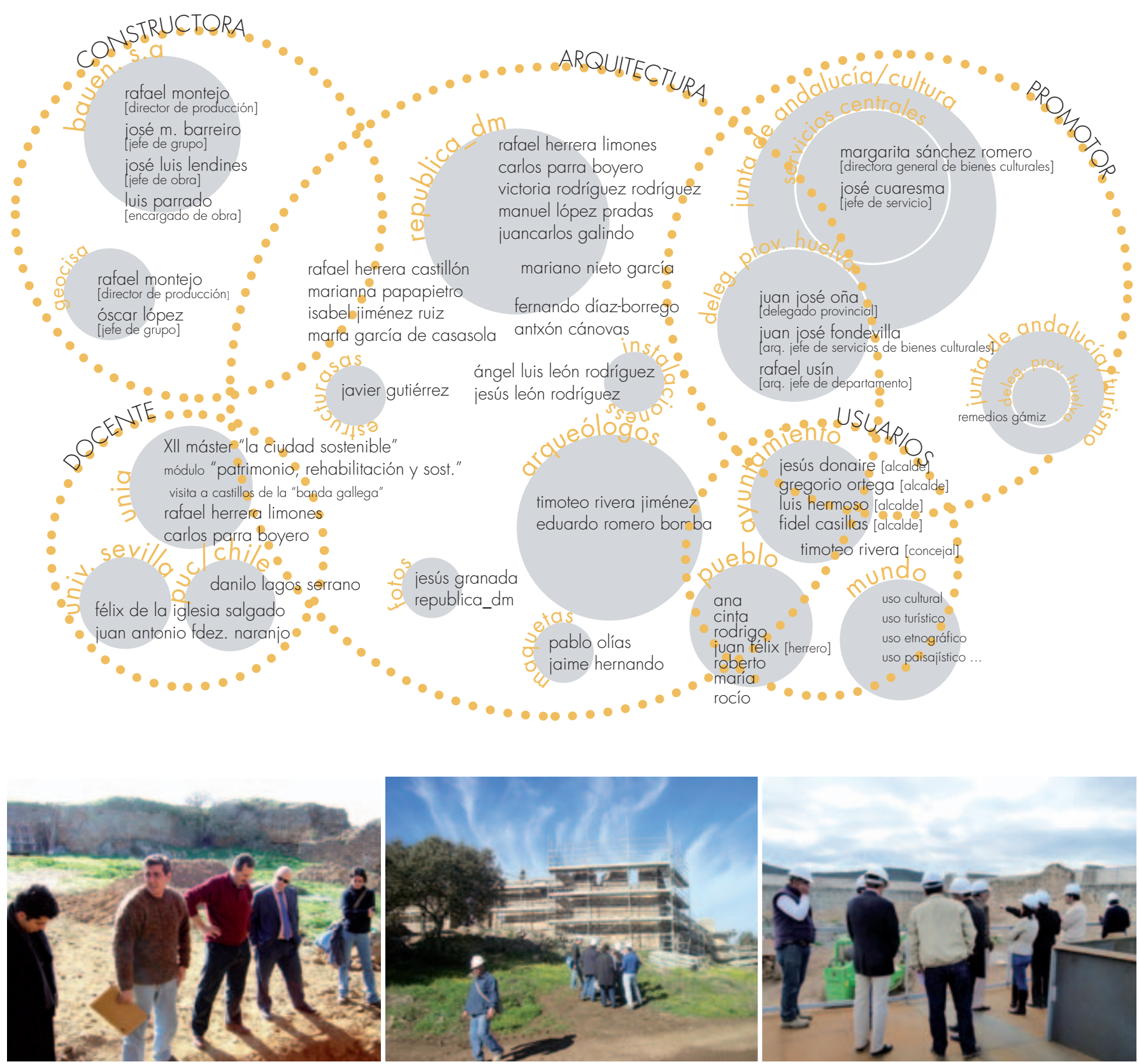

Esquema y fotos: estudio republica_dm 
De cualquier modo, nuestra idea a la hora de confeccionar el presente artículo tan sólo consiste en intentar transmitir algo más de lo que habitualmente contamos cuando exponemos una obra de arquitectura:

Intentar dar por sentado que estamos hablando de intervención arquitectónica en el patrimonio y que, por tanto, presenta unas características, de toda índole, distintas a cualquier otra tipología arquitectónica existente -o por existir-.

Intentar transmitir que, cuando trabajamos en este campo relativo al pensamiento y actuación sobre lo monumental, no constituimos, ni debemos ser, compartimentos estancos -no debiéramos serlo nunca, aunque la vorágine pre-crisis y la arquitectura del espectáculo nos hayan abocado a veces a ello-.

Intentar convencer de que la autoría ideológica y material, ejemplificada en cualquier persona o disciplina, no es relevante ni esencial $y$, además, no reflejaría la verdad de un proceso enormemente complejo y realizado por una multiplicidad de personas provenientes de diferentes disciplinas (técnicas, artísticas, docentes, políticas...).

Intentar comunicar que, al menos en lo que a nosotros nos atañe, no estamos dispuestos a dejar pasar la ocasión de expresar nuestra crítica -en el más amplio sentido del término- en cuanto a la complejidad y las múltiples ramificaciones que una actuación de esta indole posee.

Para ello, no se nos ocurre mejor comparación que la cinematográfica: utilizar aquellos clásicos apartados de "contenido extra" que todo largometraje que se precie aneja como premio al espectador fiel; pero en este caso, esa información presuntamente secundaria habrá de constituirse por sí misma en el argumento, en la causa del fin. Y a buen seguro que en nuestro caso ha sido así: la aparición en escena de cuestiones, contingencias, personas/ personajes... no constituyentes - presuntamente- del propio hecho arquitectónico que han condicionado, de una u otra forma, el devenir del proceso, tanto de pensamiento como de obra.

Pongamos un ejemplo: en el contenido extra del capítulo III de la serie cinematográfica La Guerra de las Galaxias, podemos encontrar tanto el organigrama del ingente equipo humano que intervino en la elaboración de las secuencias "estrella", como los medios y el desorbitado tiempo que se empleó en cada una de ellas.

Así, en la escena culmen de la película en la que luchan entre sí el maestro Jedi Obi-Wan Kenobi y su antiguo aprendiz Anakin Skywalker -ya abducido por el Lado Oscuro de la Fuerza-, y en la cual se intuye que se aclarará el paso de este último de personaje humano y joven bien parecido a personaje biónico y elemento central de la saga (Darth Vader), el duelo se desarrolla desde la plataforma de aterrizaje de los edificios administrativos de un planeta volcánico, Mustafar.
Obi-Wan obtiene la ventaja durante la batalla logrando posicionarse en un terreno firme más alto sobre su oponente y aconseja a su rival que se retire del duelo, puesto que la posición dominante es para él. Ante la negativa de rendirse, Anakin/Vader realiza un gran salto sobre su rival para intentar atacar a su ex-maestro por la espalda, pero Obi-Wan logra cortarle las piernas y el brazo izquierdo con su sable de luz. Mutilado, el futuro Darth Vader comienza a rodar por el terraplén y se detiene en el borde del río de lava, por lo que comienza a quemarse por el contacto con ésta.

Lo esencial para el desarrollo de la trama galáctica es que, finalmente, Skywalker es rescatado y salvado, mediante implantes cibernéticos y prótesis en sus extremidades, y la introducción en el interior de un traje metalizado negro, que le otorga una nueva apariencia robótica (con enorme presencia en el imaginario colectivo de varias generaciones de aficionados a la saga estelar). Pero lo relevante para nuestro discurso es que, en definitiva, la escena central del duelo pseudo-medieval, aliñado con características futuristas, no tiene una duración mayor de ocho minutos y, sin embargo, es la excusa para ilustrar (en el referido "contenido extra" del largometraje) un documental de más de una hora de duración, que explica tanto de manera cronológica como transdisciplinar la ideación y ejecución de los distintos segmentos que, de manera muy entre-lazada, conforman la trama y el argumento general.

En nuestro caso, salvando las distancias, podríamos establecer un símil parecido... dado que, para cada "episodio" acaecido durante la ideación y puesta en obra de la misma, podríamos elaborar un cajón de contenido extra, con las peripecias acaecidas...

\section{CRONO}

Pasar directamente a una explicación lineal y cronológica del proceso de ideación y ejecución de la intervención no implica dejar de lado cuestiones que en otro foro resultarían sumamente relevantes y que aqui, por razones obvias, no habría casi que señalar.

Pero aún así, ante el "peligro" de descontextualización que cualquier opinión puede sufrir, no está de más dejar claro nuestro firme criterio, en el sentido de que el patrimonio no debe ser tratado ni como mercancía turística ni, por el contrario, conservado en una urna, cual joya al aire libre (dado el peligro de "museificación" del que pueden ser objeto las arquitecturas del pasado, llegando incluso su transformación en parques temáticos).

Es por ello que cualquier intervención patrimonial no debe perder de vista los análisis de Aloïs Riegl, Lèvi-Strauss y otros pensadores, respecto a los valores del monumento tanto como dispositivo de memoria de nuestras sociedades, como objeto de valor intelectual y artístico; de tal modo que se dejan mucho más atrás los caducos debates en torno a criterios conservacionistas ruskinianos ("Io que se llama restauración es la peor forma de destrucción que puede sufrir un edificio") o injustificadamente intervencionistas tales 
como los propuestos por los seguidores de Viollet-le-Duc ("restaurar un edificio es restablecerlo en un estado completo que puede no haber existido nunca").

A este respecto, resultará sumamente sugerente recordar los diferentes encuentros con las fuerzas vivas de la población caliche "propietaria sentimental" del castillo (a instancias tanto del gobierno autonómico como de las distintas corporaciones munici-

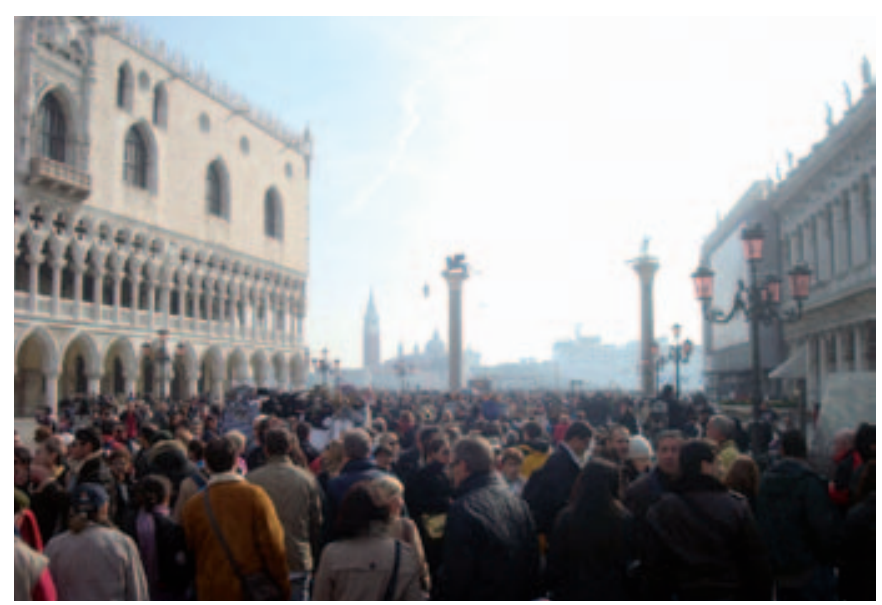

Plaza de San Marcos (Venecia). Foto: Rafael Herrera Limones

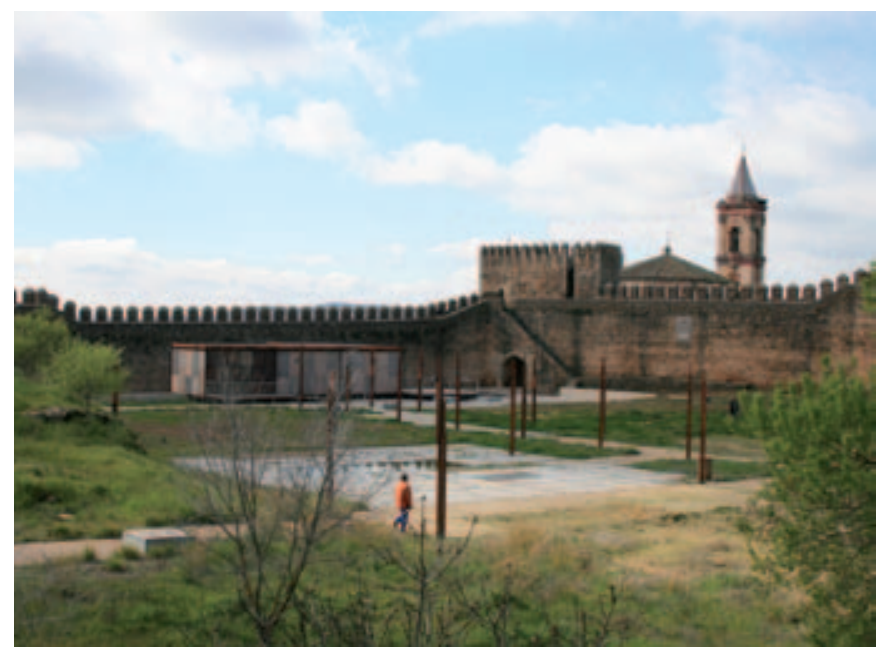

Centro de interpretación en Cumbres Mayores (Huelva)

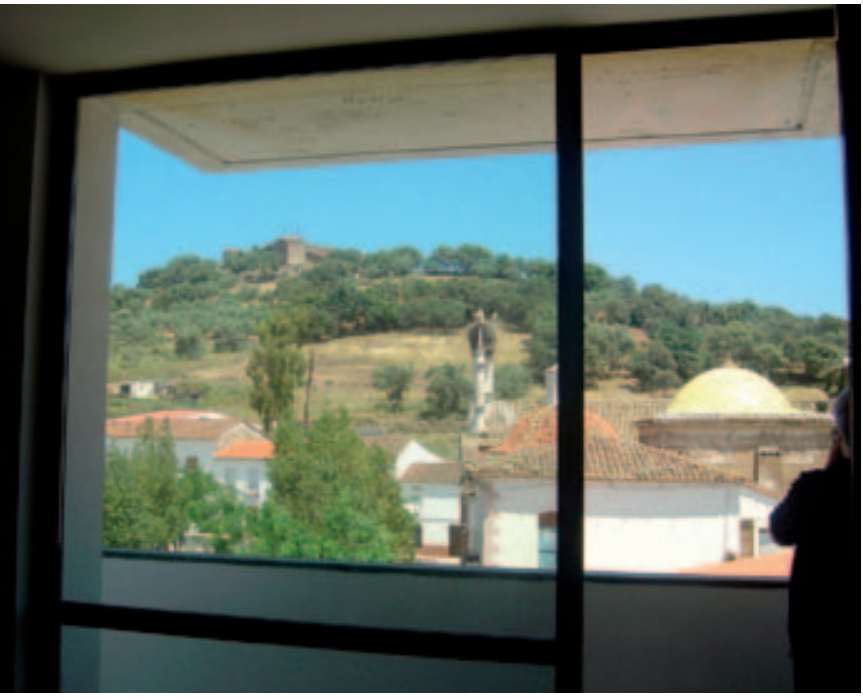

Vista del castillo de Cala desde el ayuntamiento.

Fotos: estudio republica_dm pales que, durante tan largo periodo de tiempo, han coexistido en la alcaldia), en aras a transmitirles los cambios que "su" monumento iba a sufrir, discutiendo acaloradamente el sentido de la actuación y, finalmente, obteniendo un consenso muy amplio y un convencimiento de que su visión atávica de la ruina iba a mutar hacia una percepción más acorde con la contemporaneidad.

Esta reflexión podria parecer pueril dado los trabajos, entre otros muchos, del propio Riegl, las consideraciones de Camilo Boito, de Giovannoni..., incluso tras la aprobación de las diversas cartas internacionales del patrimonio (Atenas -que recientemente cumplió sus bodas de platino-, Venecia'64, Carta del Restauro de 1972 y su revisión del 87, Cracovia'2000, etc.), la existencia de una pléyade de normativa de rango nacional y regional (Ley del patrimonio histórico español de 1985, del patrimonio histórico andaluz en 2007...), la presencia de un marco de discusión más concreto en lo relativo al patrimonio de carácter defensivo (Carta de Baños de la Encina para la conservación de la arquitectura defensiva en España de 2006 o Plan de Arquitectura Defensiva de Andalucia, por citar tan sólo algunos)...

...Tras todo ello, se podria pensar que los criterios para la intervención arquitectónica en bienes histórico-artísticos están meridianamente establecidos e, incluso, asumidos tanto por la sociedad como por quienes están políticamente al frente de ésta.

Pues bien. No es así.

En absoluto lo es. 0, al menos, no en la totalidad de los casos.

Para atestiguarlo nos bastaría con restringir el estudio a nuestra área geográfica más cercana: únicamente habria que establecer una rápida visión superficial de ciertas actuaciones que, sobre todo, se llevaron a cabo a finales del siglo pasado y principios del presente, y repasar en la hemeroteca ciertas noticias de indole cultural que escandalizan a la sociedad andaluza, curiosamente con un cierto carácter cíclico.

En la mayor parte de ellas, se pone de manifiesto de manera meridiana que lo que se espera a priori de una intervención de esta indole es que responda y colme las expectativas de los usuarios finales, en lo tocante a los atavismos de, en este caso, lo que ha de ser un castillo.

Y para muestra... un botón:

¿Cuál fue la mayor dificultad a la que nos enfrentábamos a la hora de transmitir a la colectividad social (tanto a la más inmediata - los propios habitantes de Cala-, como a la más remota) la esencia de los cambios formales en "su" castillo?

Las mayores reticencias fueron las halladas al explicar, cientificamente, que "su" fortificación no iba a tener merlones (o almenas, en lenguaje "cristiano" o castellano llano). 
"¿Y por qué no?", nos interrogaron en unas de las jornadas del patrimonio, celebradas en la población, añadiendo: "El de Santa Olalla sí tiene... Así que nosotros no vamos a ser menos".

A lo que, en honor a la verdad, hubo que responder: "Efectivamente, no sólo los tiene el del pueblo vecino, sino que han sido 'erigidos exnovo' en una no muy lejana operación de restauración; aunque, siendo más precisos, tan sólo muestran almenas aquellos lienzos concernientes a dicha operación, no así aquellos pertenecientes a la última intervención, que no los presentan".

Y a lo que cualquiera podría seguir interrogando: "Pero, por otro lado, si el mismo equipo técnico que está trabajando aquí, en Cala, es el que acaba de finalizar el Centro de Interpretación del Territorio (CIT) de la banda gallega y, en dicho castillo, el de Sancho IV, sí han dispuesto merlonado... ¿cómo justifican que en el caso del castillo de Cala no sea así?".

Llegados a este punto, habría que precisar que... "Su información no es completa: aunque este equipo de arquitectos ha participado, efectivamente, en dos intervenciones sobre el referido recinto amurallado (el mayor de la sierra onubense), hemos de señalar que incluso en la primera fase de 1994, la presencia del merlonado era ya un hecho. Dicho de otro modo: que la 'creación' de semejantes elementos pertenece a otra actuación pretérita, con criterios de intervención no coincidentes con los actuales".

"¿Entonces?" se preguntaría cualquiera, al igual que lo hicieron los habitantes caliches.

La única respuesta pertinente -y fidedigna- es la relativa a la constatación de que, según los diversos momentos históricos en los que se han acometido las actuaciones sobre el patrimonio, los conceptos prevalentes han sido distintos. Dicho lo cual, se aconseja no entrar en juicios de valor...

... aunque, en algunos casos extremos, quizá debiéramos plantearnos la oportunidad de establecer acciones conducentes a la "des-restauración" de según qué bienes, gravemente agredidos en su autenticidad.

Vaya.

Como era de esperar, ya hemos roto el relato crono¿lógico? que nos disponíamos a realizar. Bueno, tan sólo se ha adelantado una "batallita" que, posiblemente, ilustre el significado final de la historia (en el sentido de relato) que se pretende contar.

Además, si uno de los objetivos que se pretendía inicialmente era la socialización y culturización de la actuación, puede resultar de interés cómo las distintas fuerzas intervinientes en el proceso fueron convergiendo hacia un resultado que sienten, en alguna medida, suyo: no impuesto por intereses diferidos. Y no olvidemos

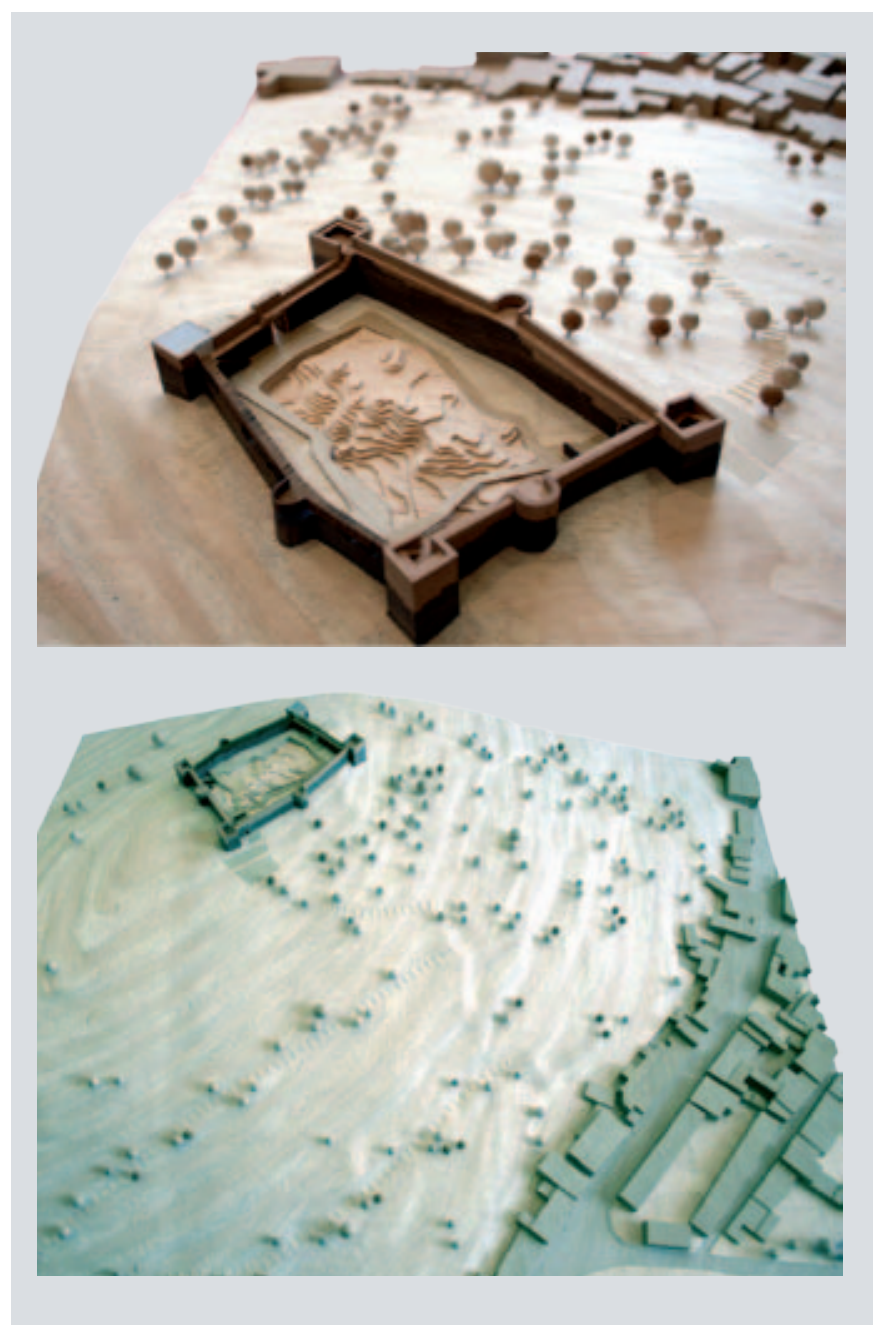

Vista de la maqueta territorial del castillo de Cala, elaborada para las XXIV Jornadas de Patrimonio. Foto: estudio republica_dm

que éste es el fin último que debe perseguir la arquitectura (y de lo que estamos hablando no es más que de arquitectura, aunque fragmentada en aras a un entendimiento de cómo la transdisciplinariedad actúa sobre ella).

\section{SIN MÁS DILACIÓN...}

Sin más dilación, pasemos al primer capitulo relevante, en orden cronológico ${ }^{2}$, de la presente historia: el documento que bajo el nombre de Avance de Proyecto Básico se redacta en 2003, por parte del estudio de arquitectura republica_dm, por encargo de la Delegación Provincial en Huelva de la Consejería de Cultura de la Junta de Andalucia, y en el que expresamente se advierte de que "Se han realizado previamente diversas excavaciones arqueológicas como estudios previos de apoyo al Proyecto de Intervención. Estas excavaciones han sido realizadas por los arqueólogos Eduardo Romero Bomba y Timoteo Rivera Jiménez".

De lo anterior se deduce que el referido documento de proyecto contenía, como parte esencial, los proyectos de intervención arqueológica realizados en 2001 y en 2003, en los que se apoyaba 

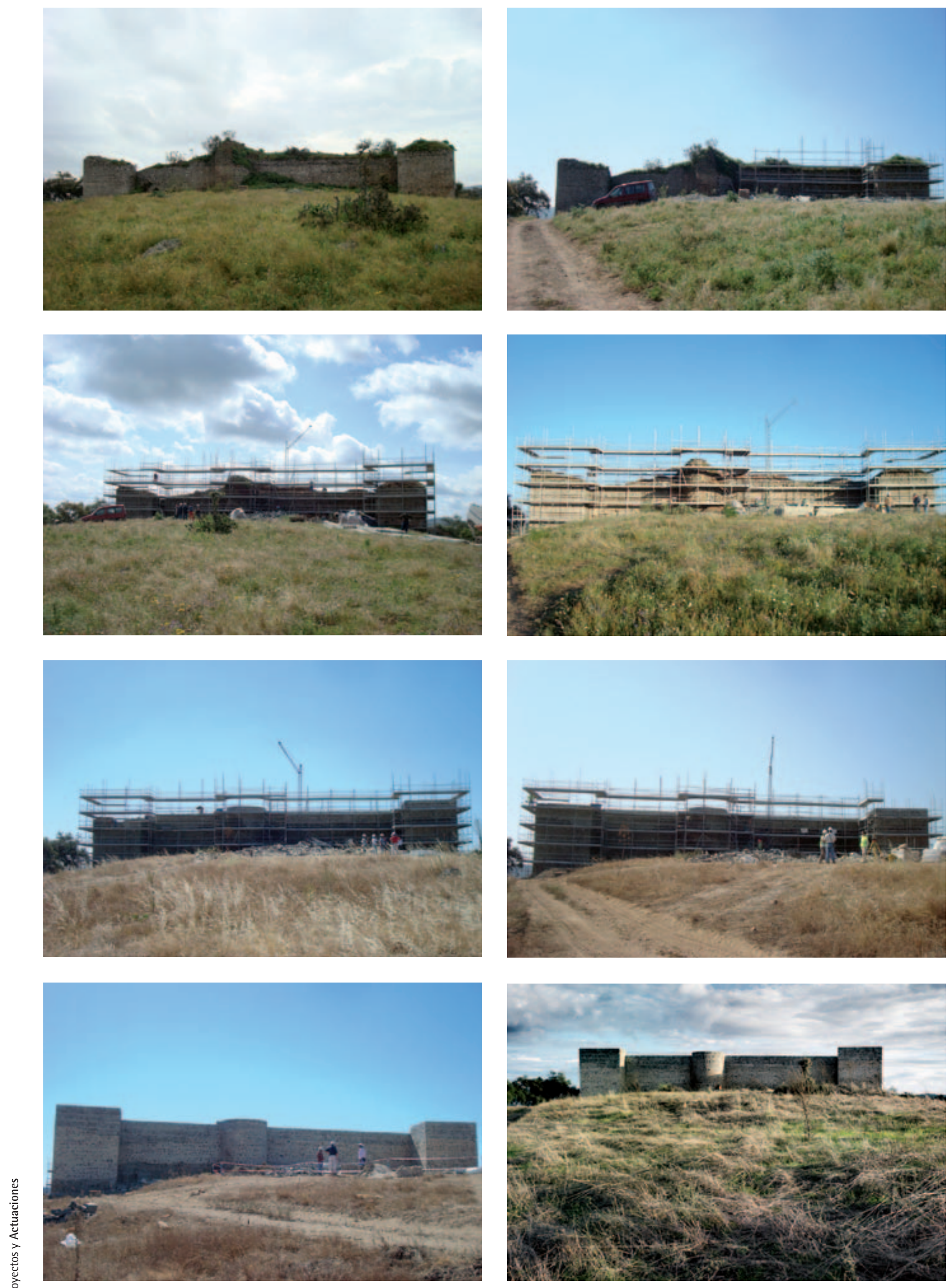

Desarrollo cronológico de las obras en el alzado norte.

Fotos: estudio republica_dm 
técnica y conceptualmente, como no podia ser de otra manera (véase la adenda/entrevista al arqueólogo Timoteo Rivera).

De hecho, aparece un párrafo que aclara que el proceso ya empieza a ser iterativo, a no ser lineal ${ }^{3}$, que merece la pena transcribir:

"En este apartado, es imprescindible señalar la estrecha, cordial y enormemente productiva colaboración entre arquitectos y arqueólogos, que se ha traducido en un trabajo de ida y vuelta, recogiendo el mejor de los sentidos de la práctica de la multidisciplinariedad, que debe implementarse como uno de los principios fundamentales para la conservación e intervención en el patrimonio construido (según la carta de Cracovia de 2000, amén de la más obvia lógica)".

En el referido avance, ya se esbozaban las líneas fundamentales de la futura actuación, basándose tanto en las referidas informaciones de carácter arqueológico, como en una exhaustiva toma de datos in situ (ver ficha técnica gráfica de p. 92), que resultó esencial a la hora del contacto físico con lo que entonces no era más que una ruina que, desde algunos puntos de vista, todavía conservaba el porte majestuoso de un castillo pero que, desde la mayor parte de las perspectivas posibles, no era más que un cúmulo de piedras desmembradas e ininteligibles en su interpretación, para todo aquél que no poseyera cualificada formación arqueológica e ingente imaginación.

En el Avance del Proyecto Básico, en definitiva, figuraba la información que a continuación se presenta, de forma resumida y actualizada, que nos es válida para explicar tanto los antecedentes históricos del $\mathrm{BIC}$, como el estado de conservación del inmueble previo a la intervención; igualmente, se avanzan -como ya se ha dicho- las líneas generales de la intervención arquitectónica que supondrá el esqueleto conceptual que subyace intrínseco en el resto de fases de proyecto, e incluso en el proceso de obra posterior.

Antecentes históricos del castillo:

El castillo de Cala es una de las fortificaciones medievales que se conservan en la comarca serrana de Huelva, que historiográficamente fue definida como perteneciente a la banda gallega -formación del sistema defensivo del Reino de Sevilla contra eventuales ataques portugueses-. Entre los castillos de Cala, Real de la Jara y Santa Olalla de Cala se establece un control visual, de forma triangular, en una zona limítrofe con los territorios de la orden de Santiago y que es atravesada por la Vía de la Plata, lo que resulta de vital importancia geo-estratégica.

Se estima para su construcción una cronologia en torno a finales del s. XIII y principios del s. XIV4.

Descripción hipotética del inmueble:

La fortaleza se levanta sobre un cerro de unos $650 \mathrm{~m}$ de altitud, con pequeña meseta en su cumbre. El paisaje de su entorno co- rresponde a una dehesa y a sus pies se extiende la vega de la rivera del río Cala. El conjunto tiene unas dimensiones reducidas y está aislado totalmente respecto de la población. Seguramente tuvo la función de albergar a una pequeña guarnición militar, no a la propia población.

El castillo de Cala tiene planta irregular, pero tendente a rectangular. Es un recinto cerrado por lienzos de muralla de anchura variable, que oscila entre 1,93 y 2,16 metros. Tiene una torre de planta cuadrangular en cada esquina y otras semicirculares intermedias en tres de sus lados. Existe una impresión de convexidad en los dos lados de mayor longitud, sobresaliendo las torres intermedias, pero los lienzos presentan un trazado rectilíneo entre las torres.

Debió existir una puerta principal situada al sur, limitada por dos muros perpendiculares a la muralla y probable matacán corrido, con dos arcos (de medio punto y apuntados) y bóveda de cañón. Presenta, en relativo buen estado de conservación, una puerta secundaria (poterna) situada al oeste, con arco interno de medio punto y arco externo ojival de sillares de granito enmarcado en un rehundimiento rectangular; entre los arcos, se ubica una bóveda de cañón de sillares de granito, nivelados con hiladas de ladrillo.

Existen dos escaleras interiores, adosadas a los muros: una cercana a la puerta principal adosada al lienzo SE, asciende en dirección NE y desembarca finalmente en la esquina que forman los lienzos y la torre; y otra, junto a la poterna, que se adosa al lienzo de muralla NW y asciende en dirección SW.

Los lienzos de muralla están construidos con dos muros de mampostería careada, rellenos el hueco intermedio con tierras, arcilla, piedras y argamasa de cal. Los lienzos de muralla se levantan sobre el afloramiento rocoso.

En cualquier caso, el sistema constructivo es similar al de otras fortalezas serranas tales como Encinasola, Torres, Cortegana, Cumbres de San Bartolomé, Cumbres Mayores o Santa Olalla.

Según se deduce de los análisis realizados, la torre ubicada a la derecha de la puerta principal, desde el exterior, presentaba una estancia en su parte superior.

\section{Estado "actual":}

El recinto fortificado presentaba un estado de ruina general. Ya en 1788, en una entrevista que realiza el geógrafo real Tomás López y que responde el bachiller José Rodríguez, se señala "(...) esta villa conserva un castillo arruinado".

A los lienzos de muralla y a las torres les faltaba tanto el elemento de remate como, en general, toda la zona superior. En la intervención arqueológica se avanza como hipótesis la existencia de una 

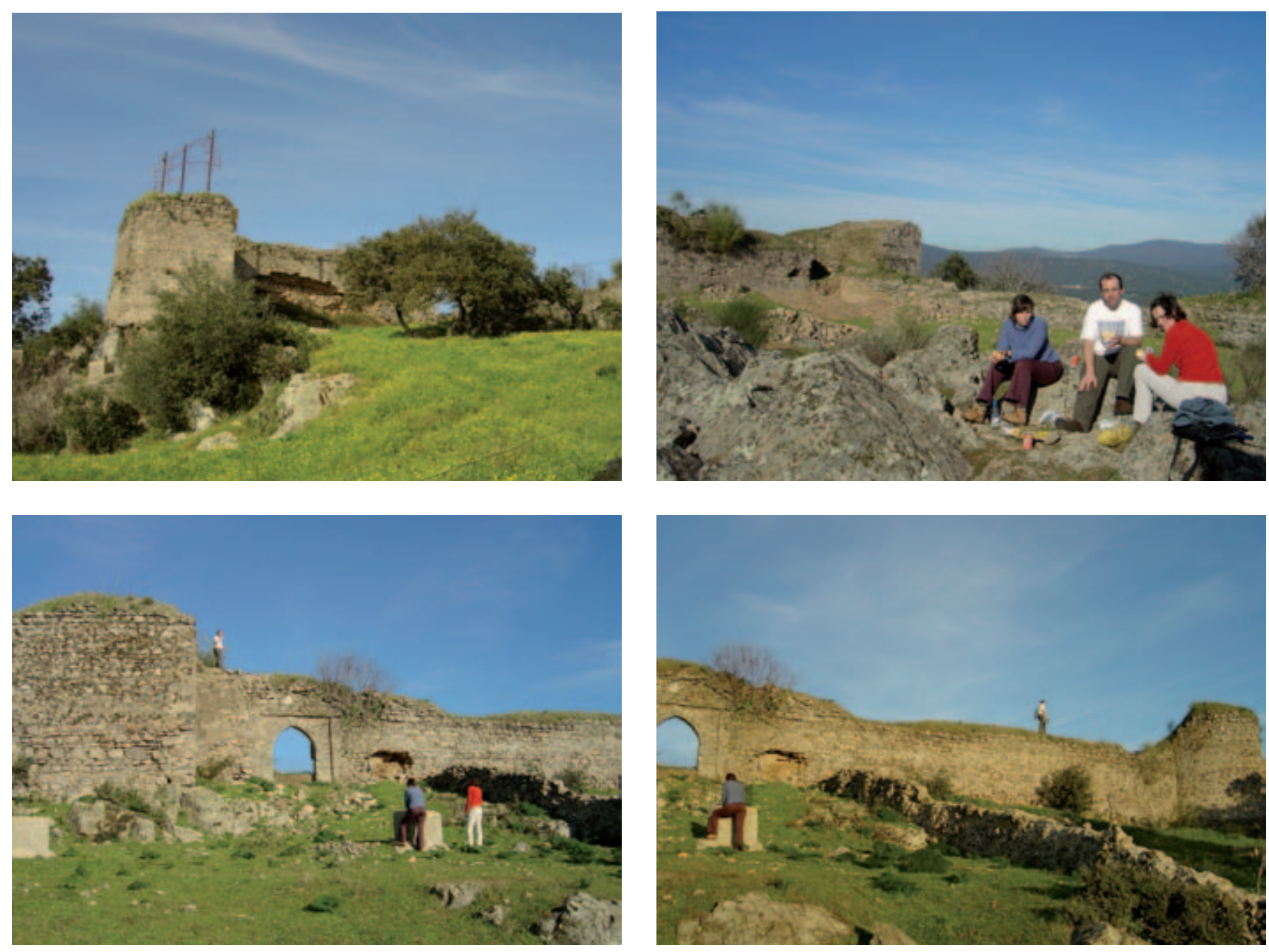

Imágenes relativas al proceso de toma de datos, en las que se observa el estado ruinoso del conjunto, así como la mimetización con el territorio del interior del patio de armas. Fotos: estudio republica_dm

protección o peto corrido en la parte exterior, tanto en el paseo de ronda como en las torres, ya que no se ha podido documentar la existencia de pináculos y merlones. Existían en los lienzos de muralla y en las torres gran cantidad de deterioros en la mamposteria, con grandes oquedades, y falta de material. La puerta principal textualmente no existía, al estar destruido por completo el lienzo de muralla al que se adosaba. Igualmente, los restos de las dos escaleras por las que se accedería al paseo de ronda se encontraban en estado ruinoso.

El castillo presentaba un importante relleno interior, principalmente de material de derrumbe, e igualmente acumulación de materiales procedentes de la destrucción de las estructuras internas existentes en el castillo. Sin duda, el relleno ejercia sobre los paramentos una presión perjudicial desde el punto de vista de la estabilidad.

Los paramentos y zonas inmediatas a las murallas se encontraban muy afectados de vegetación espontánea y materia ajena acumulada, tanto al interior como al exterior del recinto, y también en la coronación de los lienzos. Igualmente, en las llagas de la fábrica había multitud de brotes vegetales parásitos produciendo gran deterioro en dichas zonas.
Memoria de actuación:

Aunque el estado general de ruina del castillo planteaba numerosos interrogantes respecto a determinados aspectos constructivos, sí existían suficientes datos para plantear su restauración integral, que pasaba fundamentalmente por la reparación de los daños y por la puesta en valor del conjunto monumental mediante la recuperación volumétrica a gran escala del conjunto, así como el rescate de aquellas cotas de uso documentadas.

Es prioritario destacar que, aun pretendiendo recuperar el contorno general del conjunto, se trataba de un elemento patrimonial inserto en un paisaje que por lo tanto debe ser tratado desde criterios de intervención en éste.

Se planteó llevar a cabo, entre otras, las siguientes actuaciones: tratamiento para eliminar la materia ajena existente en paramentos y coronación, consolidación de paramentos murarios con pérdidas y degradaciones, recuperación de las cotas de uso del paseo de ronda, y excavación en área abierta del interior del recinto, definiendo el nivel original fijado en las últimas intervenciones arqueológicas 5 . 

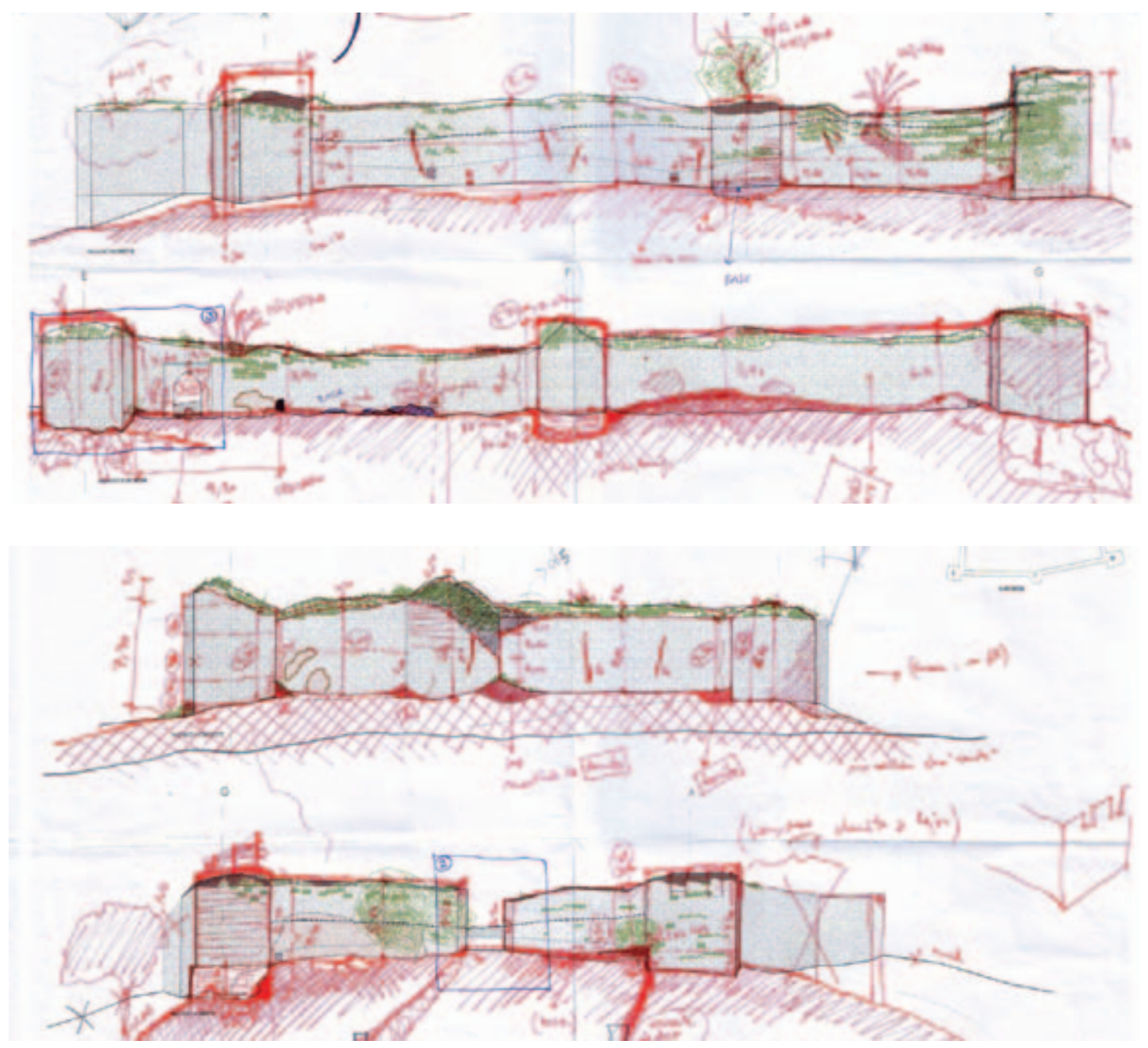

Re-croquis del proceso de toma de datos y estudios previos de los alzados. Fuente: estudio republica_dm

\section{EN EL PROYECTO BÁSICO...}

En el Proyecto Básico de 2004, se profundiza en las cuestiones ya esbozadas con anterioridad -gracias al conocimiento exhaustivo que ya se posee del inmueble-, se incorporan las observaciones realizadas por la Comisión de Patrimonio de la Delegación Provincial, y se insiste en los principios que deben guiar la intervención. Entre ellos se destaca la aplicación rigurosa de la Carta de Cracovia de 2000; en ésta, y dentro de la enumeración de los principios para la conservación y restauración del patrimonio edificado, se establece (en su apartado no 4 ) que:

"Debe evitarse la reconstrucción en 'el estilo del edificio' de partes enteras del mismo. La reconstrucción de partes muy limitadas con un significado arquitectónico puede ser excepcionalmente aceptada, a condición de que ésta se base en una documentación precisa e indiscutible. Si se necesita, para el adecuado uso del edificio, la incorporación de partes espaciales y funcionales más extensas, debe reflejarse en ellas el lenguaje de la arquitectura actual (...)".

Asimismo, se empiezan a detallar asuntos y cuestiones constructivas más propias de la escala menuda -o del detalle arquitectónico-, frente a lo realizado hasta ahora, más del lado de la escala territorial.
Esta doble mirada, macro y micro, ejemplifica bien a las claras la dificultad de este tipo de intervenciones en bienes patrimoniales, dado que tanto una como otra coexisten de una manera mucho más relevante que en otro tipo de actuaciones arquitectónicas, debiendo ambas procurar la justa atención dentro del proyecto global.

Todo lo anterior se acaba traduciendo en las siguientes líneas de actuación:

En lo concerniente a la volumetria general:

1. Recuperación de los tres tramos murarios (los situados en el NO, SO y SE) que "ofrecen fachada" a la población, y que constituyen la memoria colectiva y consciente de su pasado: el atavismo etnográfico de la ciudadanía. Dicha operación se plantea mediante un lenguaje constructivo tal que permita una doble lectura del BIC: a) Desde el punto de vista de su integración en el entorno-territorio-paisaje, mediante los materiales utilizados, con texturas y tonalidades generales, que no difieran sustancialmente de los preexistentes; b) Desde el punto de vista de la autenticidad e integridad del inmueble, pudiéndose diferenciar claramente los distintos lenguajes (el primigenio y el utilizado en la intervención arquitectónica), de manera que no se produz- 
can efectos indeseados de mimesis, ni tampoco se produzcan éstos con el paso de los años.

2. En el tramo de muralla comprendido entre las torres $A$ y $C$ (el lienzo orientado al NE), se considera por una parte que, dado que se encuentra "de espaldas" a la población que ampara el castillo, y "de cara" a la ladera con mayor pendiente y de más lejana perspectiva; $y$, por otra parte, con el objeto de potenciar la autenticidad de los restos históricos existentes, es oportuna una recuperación espacial con materiales diferentes a los preexistentes, "conservando" el estado de "ruina" y materializándose en una pasarela ligera, que permite el registro y la continuidad del paseo de ronda en sus cotas primitivas (según las hipótesis de uso), recuperando, igualmente, la volumetria virtual preexistente.

En lo concerniente al patio de armas:

1. Se establece una "línea de relleno = cero", a partir de la cual (y junto a la consideración de los desagües existentes), se incorporan unos recorridos y usos que permiten la puesta en valor del interior del recinto amurallado 6 .

2. Se recuperan los accesos al paseo de ronda mediante sendas escaleras, ubicadas en los lugares precisos que ocupaban las originales, utilizando dimensiones, proporciones, y materiales que aporten ligereza y diferenciación con lo patrimonial existente.

3. Se estipula el mantenimiento y explotación de las unidades de intervención más importantes derivadas de los estudios arqueológicos.

Criterios constructivos de la intervención:

En el proceso de restauración del castillo, se emplean técnicas y materiales contemporáneos que, dentro de lo posible, tengan resultado similar al obtenido con las técnicas primitivas a nivel de conjunto. En definitiva: que se establezcan de forma clara las diferencias entre lo existente y lo añadido, aunque el aspecto general del edificio halla de ser unitario y se reconozca su forma primigenia.

En las consolidaciones por pérdidas y degradaciones, se emplean piedras de pórfido riolítico, que es el material del propio afloramiento rocoso, junto a la piedra natural del entorno. Además, se restringen las intervenciones que suponen aumento excesivo de las cargas de los lienzos murarios.

\section{TRAS LA CONCLUSIÓN DEL DOCUMENTO...}

Tras la conclusión del documento relativo al proyecto básico elaborado por encargo de la Consejería de Cultura de la Junta de Andalucia, se recibe una encomienda por parte de la Consejería de Turismo, Comercio y Deportes, consistente en la creación de senderos peatonales en la ladera del castillo y el diseño de zonas de estancia en puntos panorámicos que facilitasen tanto la lectura del paisaje y del bien patrimonial, como el acceso a éste desde la población.

Las razones políticas de dicha actuación -que no vienen al casoprovocan que se elabore un documento técnico y se acometa una obra por parte de este equipo que, en pura lógica constructiva, debiera haber tenido lugar tras las obras en el castillo.

En cualquier caso, estas actuaciones evidenciaron la problemática que existía en cuanto a la propiedad de los terrenos colindantes al castillo, que hacía realmente inverosímil el concepto de "ámbito de BIC" aplicado a esta edificación: tres cuartas partes de los terrenos colindantes a los lienzos murarios eran de propiedad privada.

De hecho, durante el período de tiempo transcurrido hasta el comienzo de los trabajos en el castillo, se emprendieron acciones por parte de la municipalidad local -con el apoyo del gobierno autonómico-, que condujeron exitosamente a la compra de la mayor parte de las haciendas colindantes.

\section{EN EL COMPÁS DE ESPERA...}

En el compás de espera para la autorización de elaboración del proyecto de ejecución (en torno a tres años), tuvieron lugar dos acontecimientos extremadamente relevantes para el hecho arquitectónico en España: la aprobación del Código Técnico de la Edificación (CTE) en 2007; y para la concepción y puesta en valor de los castillos y recintos amurallados de nuestro territorio, la implementación del Plan de Arquitectura Defensiva de Andalucía (PADA) de 2006, que condicionaron sin lugar a dudas el devenir de los trabajos.

EI CTE aportó a la intervención arquitectónica sobre el patrimonio histórico un debate relativo, entre otras cosas, a cuestiones relacionadas con la seguridad, ejemplificado en el congreso que sobre esta temática tuvo lugar en el seno del Instituto Andaluz del Patrimonio Histórico. El PADA, por su parte, situó la problemática de la arquitectura defensiva andaluza en un entorno de mayor rango, poniendo en relación los distintos elementos en el entramado existente. Ello permitía que la investigación se nutriera de mayor número de casos de estudio, lo que repercute finalmente, sin duda, en la mayor certeza en cuanto a las conclusiones obtenidas.

\section{DE CUALQUIER MANERA...}

De cualquier manera, finalmente, tras diversos avatares de indole económica, política, social..., tras la preceptiva aprobación de la Comisión de Patrimonio (febrero de 2007), el acatamiento de las recomendaciones de la misma, y sucesivos informes de supervisión (con aprobación definitiva en agosto de 2008), el documento 


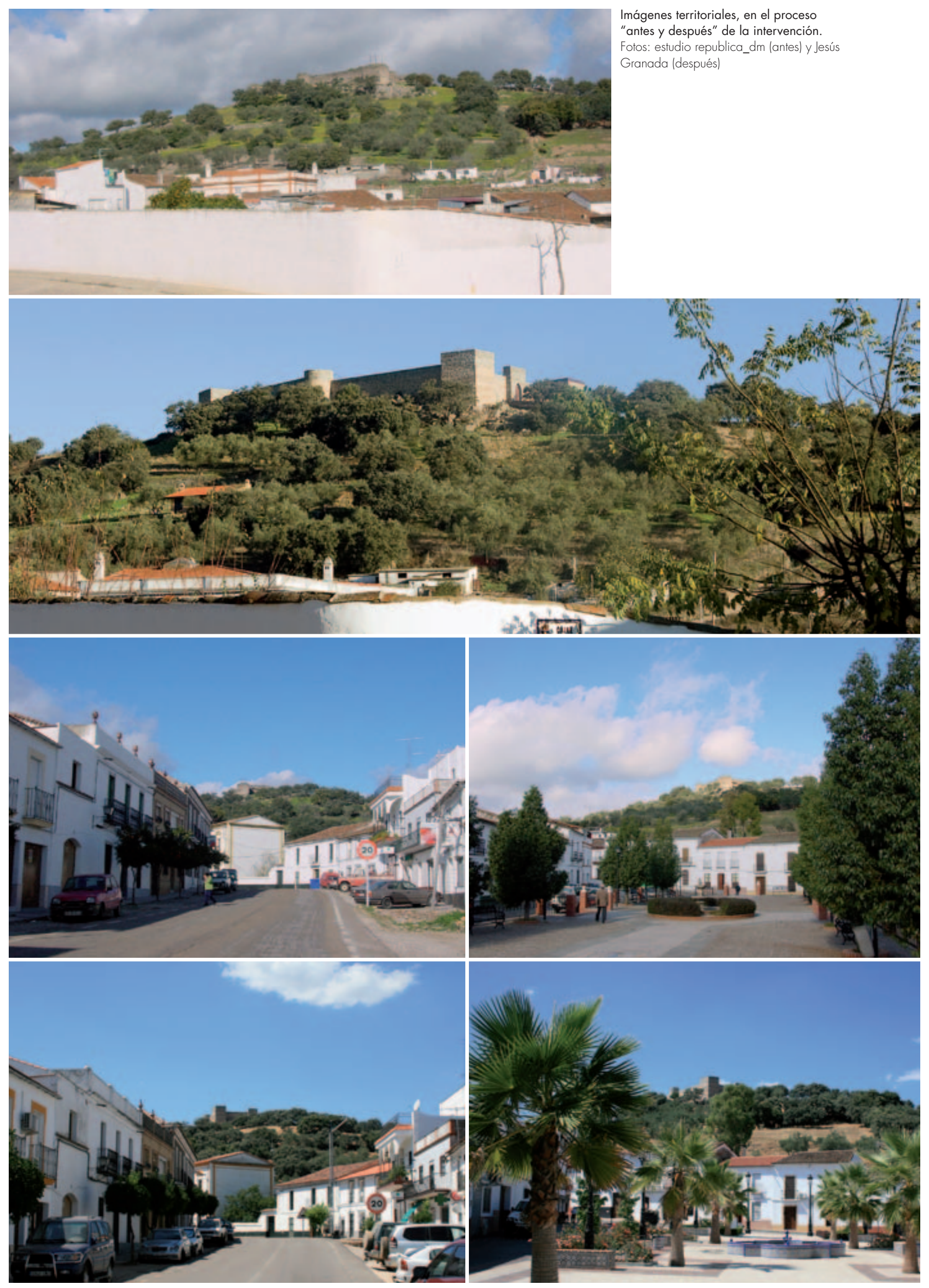



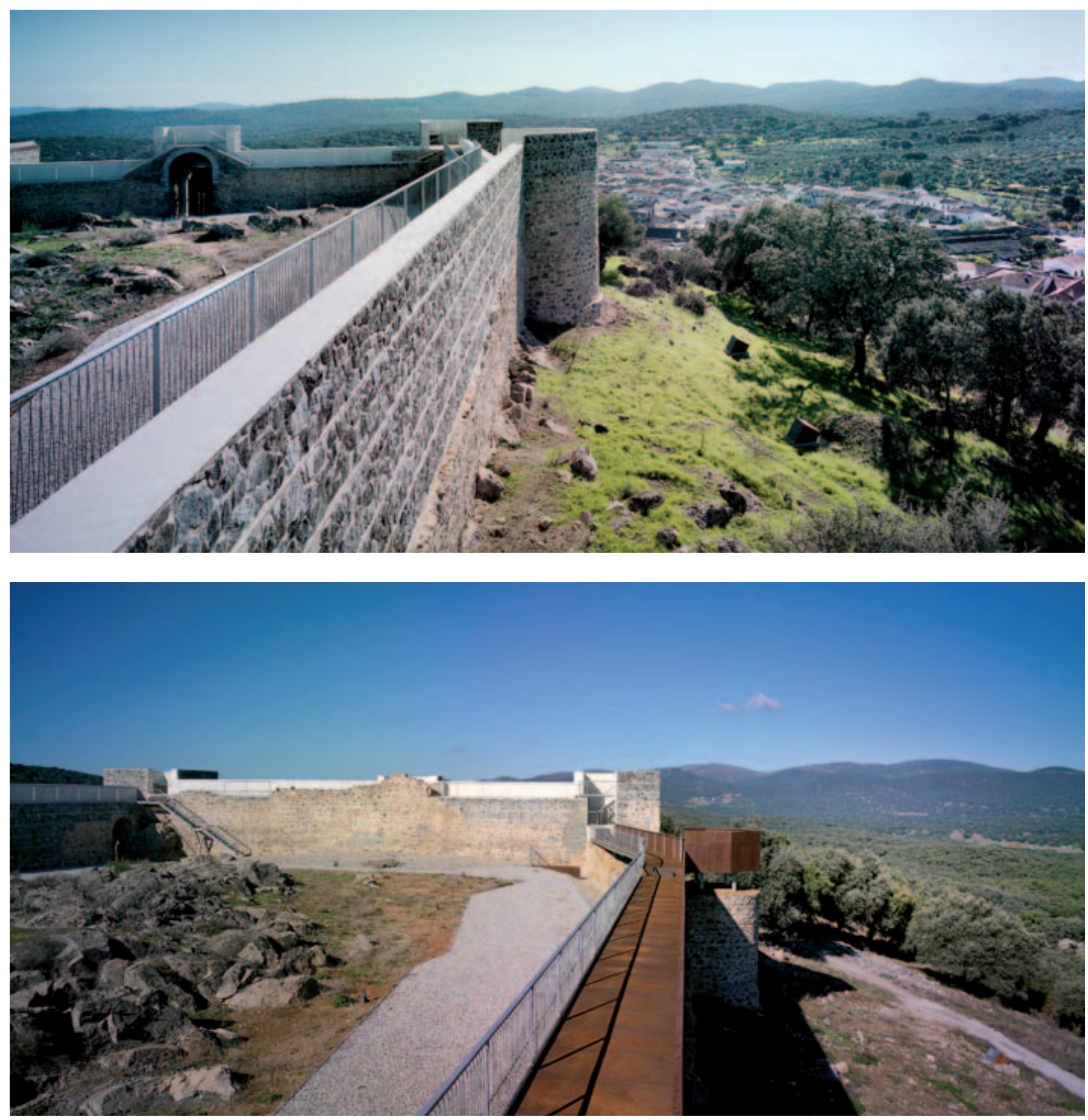

Lienzo y paseo de ronda a la población (arriba) y al territorio -lienzo NE- (debajo). Fotos: Jesús Granada

En lo que respecta al lienzo $N E$, se concreta constructivamente mediante la implementación de una pasarela ligera de acero tratado con ácido, y con posterior fijación del óxido, para que asuma una coloración acorde con las tonalidades del resto del paramento y del territorio 
bajo el epígrafe Proyecto de Ejecución de Intervención en el castiIlo de Cala (Huelva) se encuentra listo y preparado para ser puesto en carga mediante la oportuna dirección de obra.

En él se recogen y amplian las cuestiones más relevantes de los estadíos anteriores de proyectos, y se acaban de concretar las disquisiciones definitivas en cuanto a las técnicas y soluciones a emplear. Así por ejemplo, en cuanto a la recuperación volumétrica de los lienzos de la muralla, se definen cinco cotas distintas para el adarve, condicionadas por los afloramientos rocosos que sirven de cimentación a los lienzos (según las técnicas edilicias de construcción halladas en los estudios arqueológicos).

En cuanto a los lienzos que "ofrecen fachada" a la población que, tal como se ha dicho, constituyen la memoria colectiva de su pasado y, contemporáneamente se configuran como hitos paisajísticos, se concretan estructuralmente utilizando el mismo concepto de sistema constructivo edilicio: dos rostros de piedra y una matriz compactada.

En lo que respecta al lienzo NE, se concreta constructivamente mediante la implementación de una pasarela ligera de acero tratado con ácido, y con posterior fijación del óxido, para que asuma una coloración acorde con las tonalidades del resto del paramento y del territorio.

Todo ello se plantea, tal como ya se ha avanzado, desde el punto de vista de la autenticidad e integridad del inmueble, en aras a diferenciar claramente la parte intervenida, de manera que no se produzcan efectos indeseados de mimesis, ni siquiera con el paso de los años.

Finalmente aparecen, como es preceptivo, toda una serie de detalles y evidencias de la escala micro, que avalan el carácter dual de las actuaciones.

\section{EN EL PERÍODO TEMPORAL...}

En el periodo temporal que existió entre los diversos trámites administrativos y el comienzo de las obras (en abril de 2010), se produce un hecho enormemente relevante que reafirma la tesis de la premura y la necesidad de la intervención, aunque ésta sólo fuera de consolidación: es el derrumbe que se produce en la denominada "cueva de Taranzo", junto a la puerta principal del castillo.

Ello provoca la aparición de lo que se llamó Informe de emergencia, redactado tras la recepción en nuestro taller del siguiente mensaje:

"En visita realizada recientemente, pudimos constatar la gravedad del asunto. Por el rudimentario método del palo, se comprobó la conexión directa entre la grieta interior y el boquete exterior: sale en la vertical de la zarza y algo más arriba. Entendemos que la
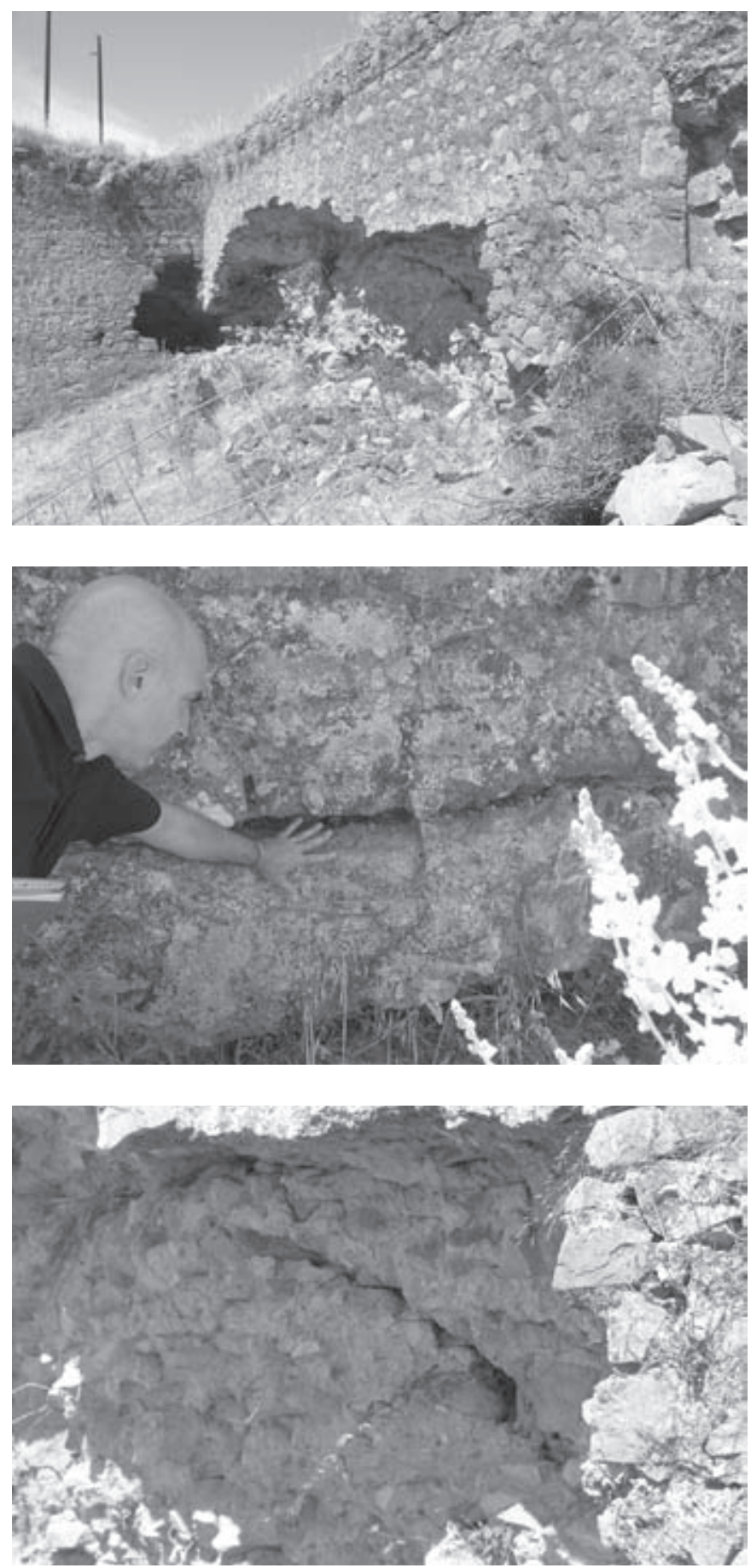

Imágenes del derrumbe y grietas en la "cueva de Taranzo" Fotos: estudio republica_dm

solución, más que el apuntalamiento sine die, seria la intervención de forma inmediata, puesto que ya sabemos cuál es el tratamiento en esa zona del lienzo".

De seguro que lo acontecido respecto a la inminente ruina del lienzo referido condicionó y priorizó el comienzo de las obras en Cala, frente a otras posible intervenciones que la Administración Pública tuviera incorporadas en programación. Además, con el proceso de crisis ya en estado de consolidación y avance, es posible que, de no haber ocurrido semejante episodio, la operación hubiera sido pospuesta 0 , incluso, nunca se hubiera llevado a cabo. 


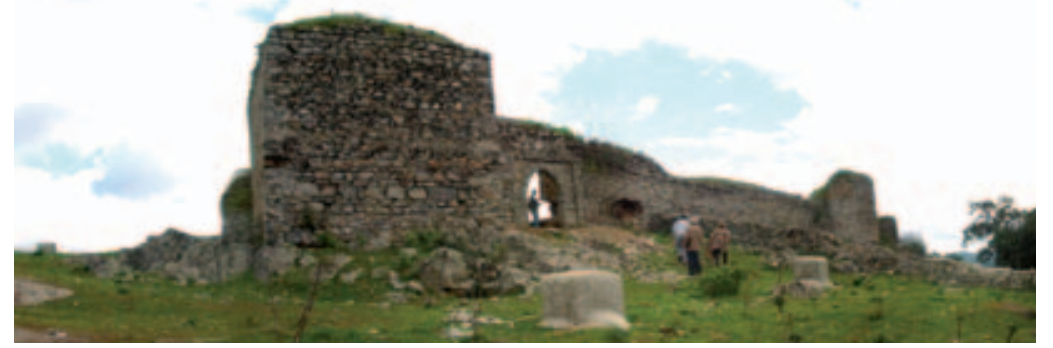

Vistas comparativas del proceso de intervención, de los lienzos urbanos y de los territoriales.

Fotos: estudio republica_dm (antes) y Jesús Granada (después)
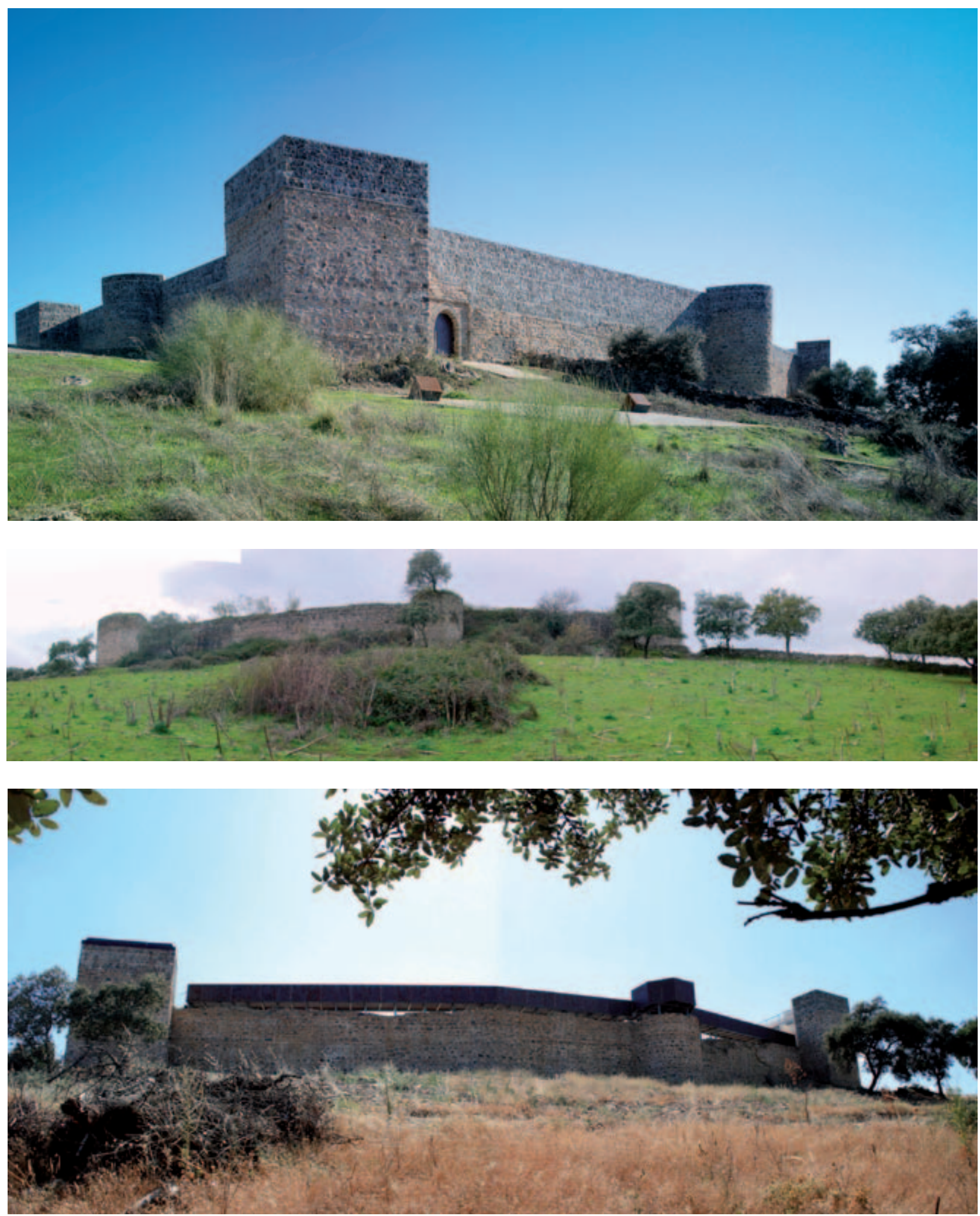


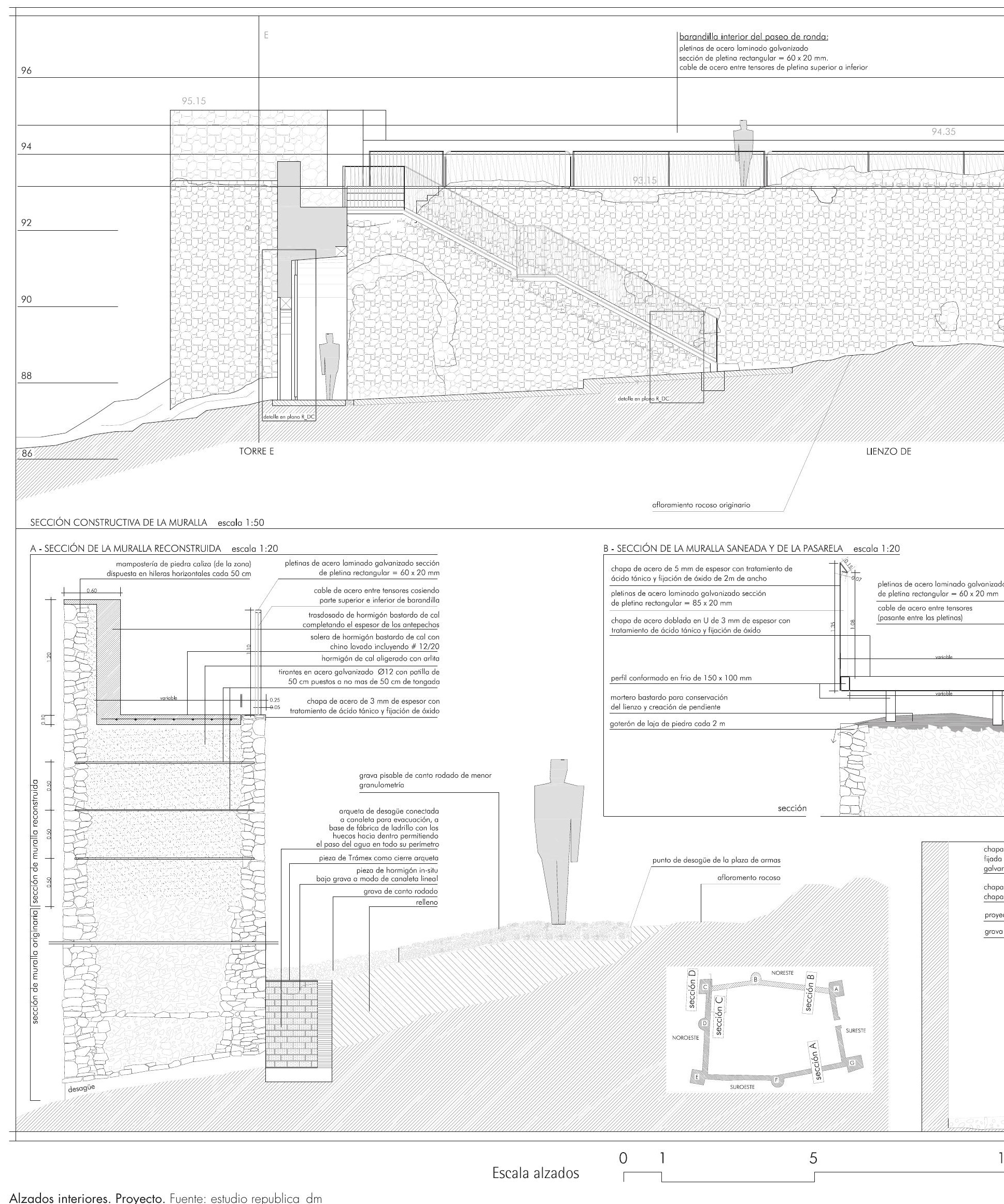




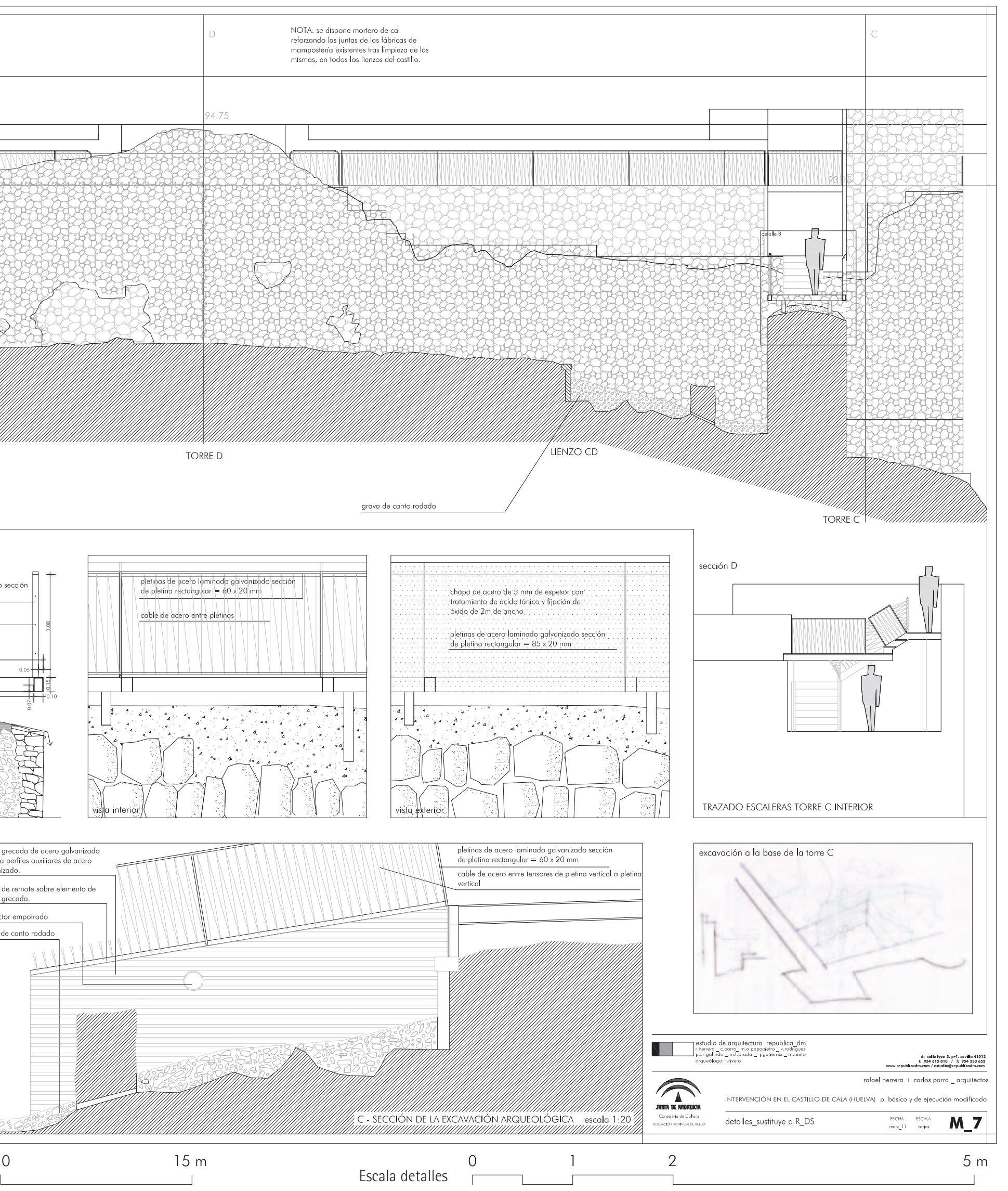



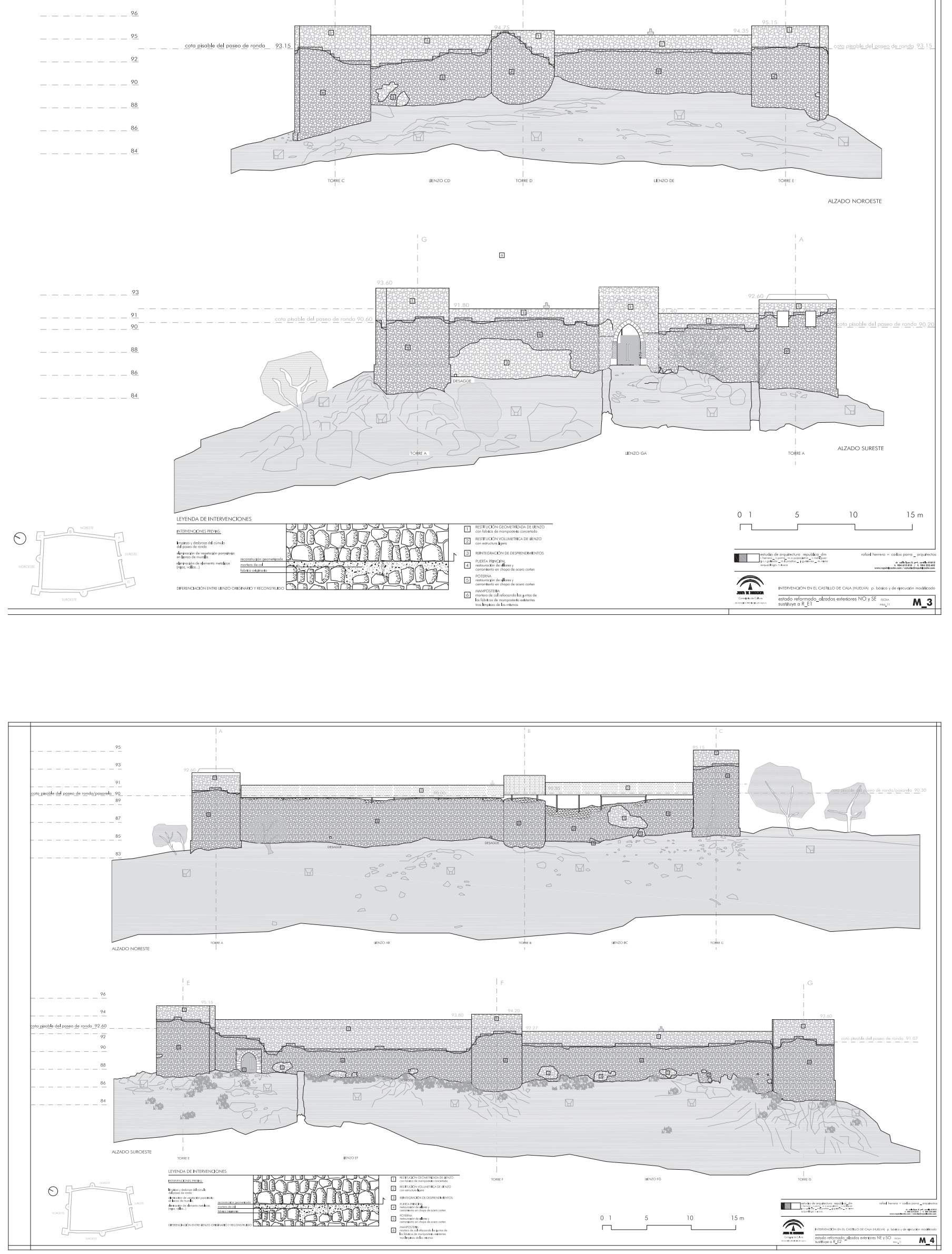

Alzados exteriores. Proyecto. Fuente: estudio republica_dm 


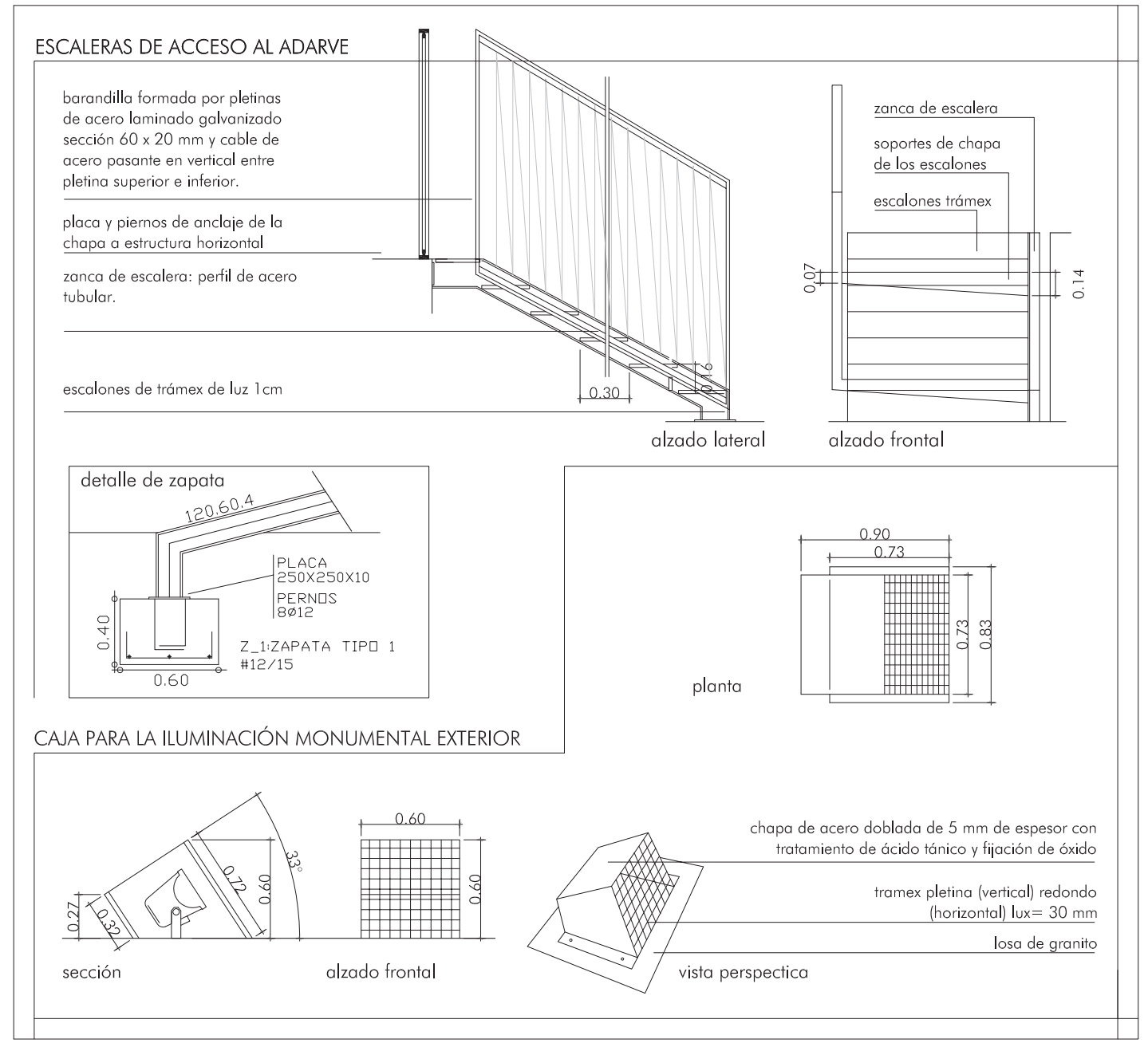

Detalles cerrajería. Proyecto. Fuente: estudio republica_dm
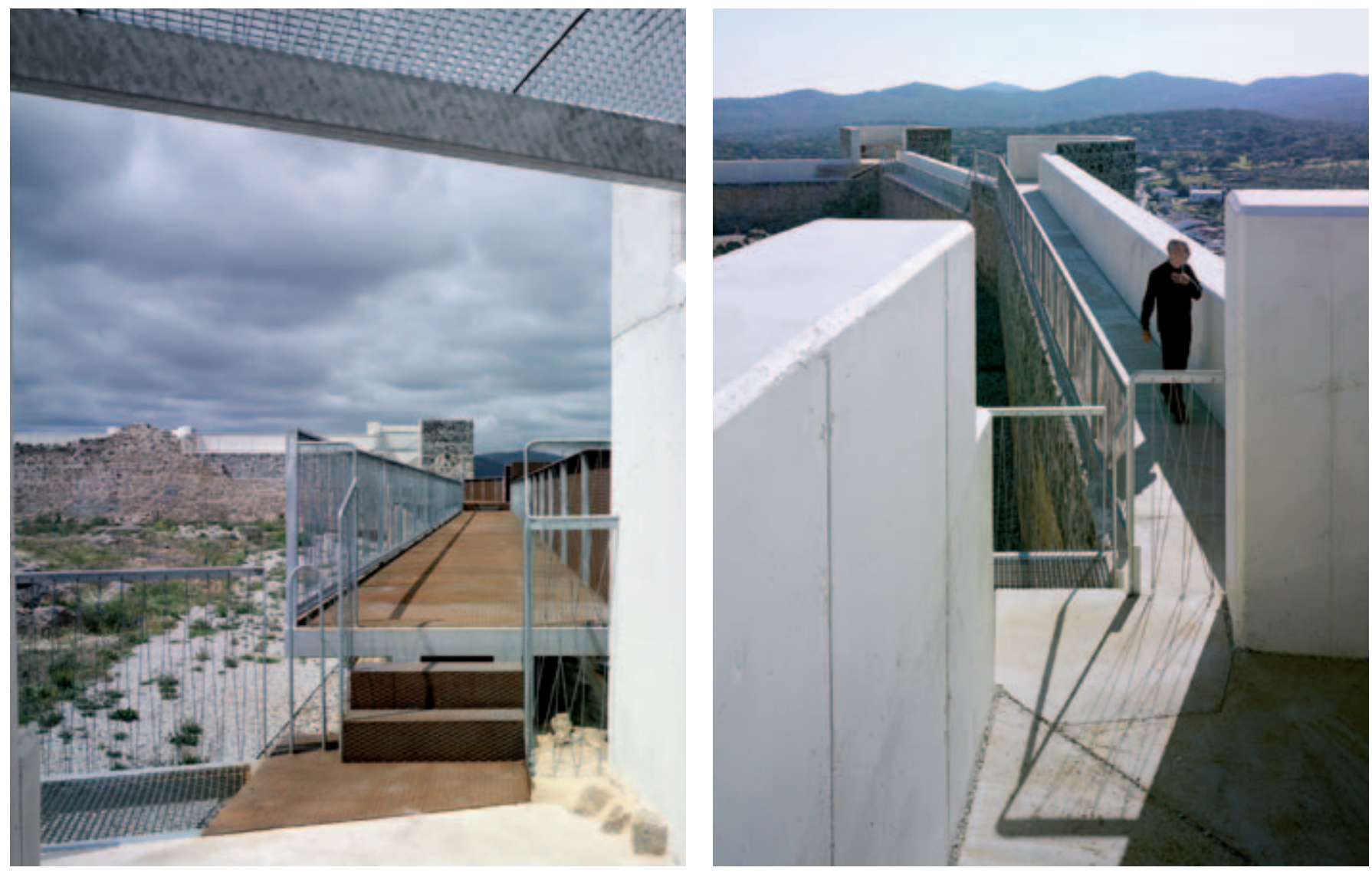

Detalles del paseo de ronda y del interior de las torres cuadrangulares. Fotos: Jesús Granada 

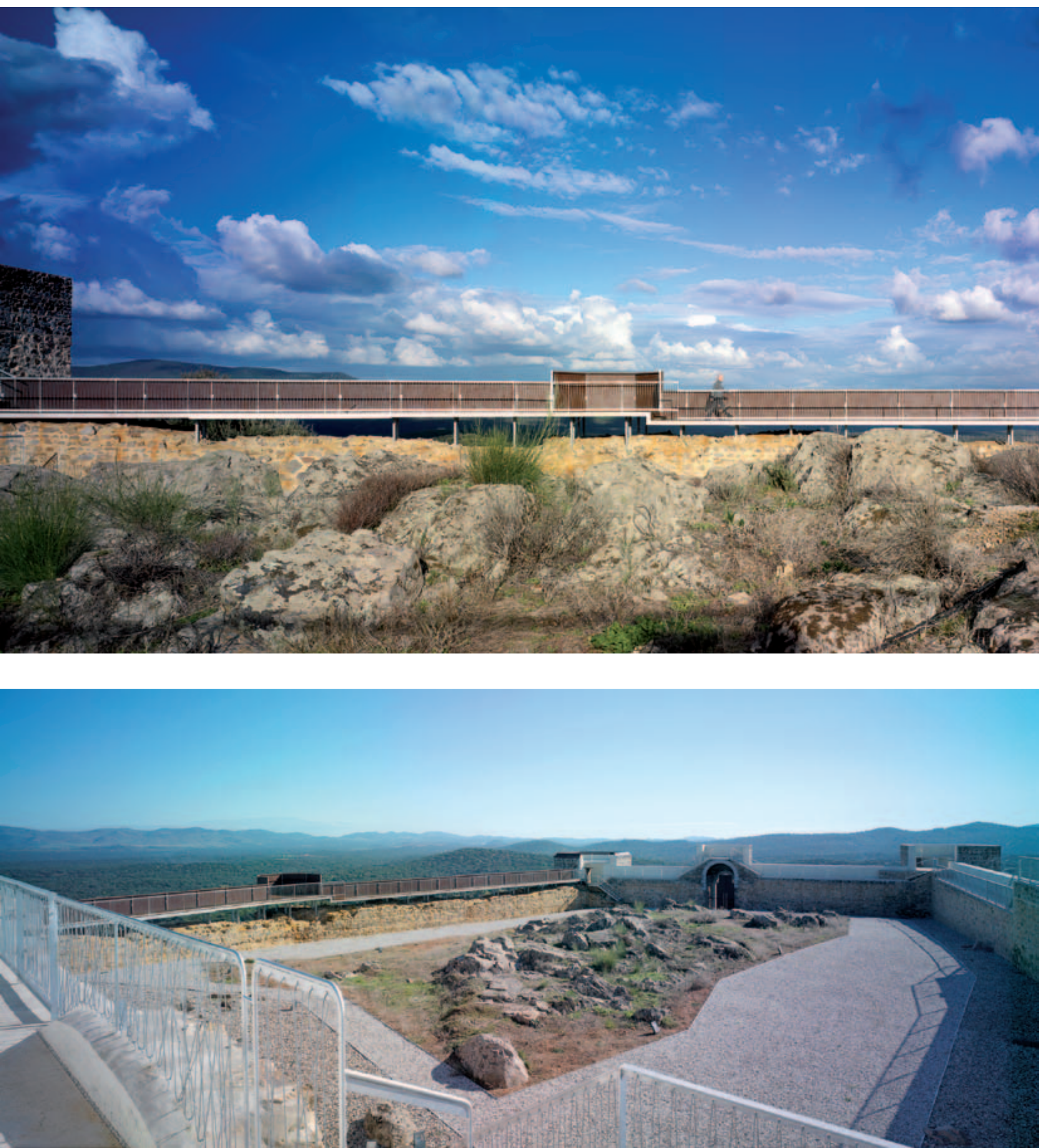

Vistas del interior del recinto amurallado (patio de armas). Fotos: Jesús Granada 

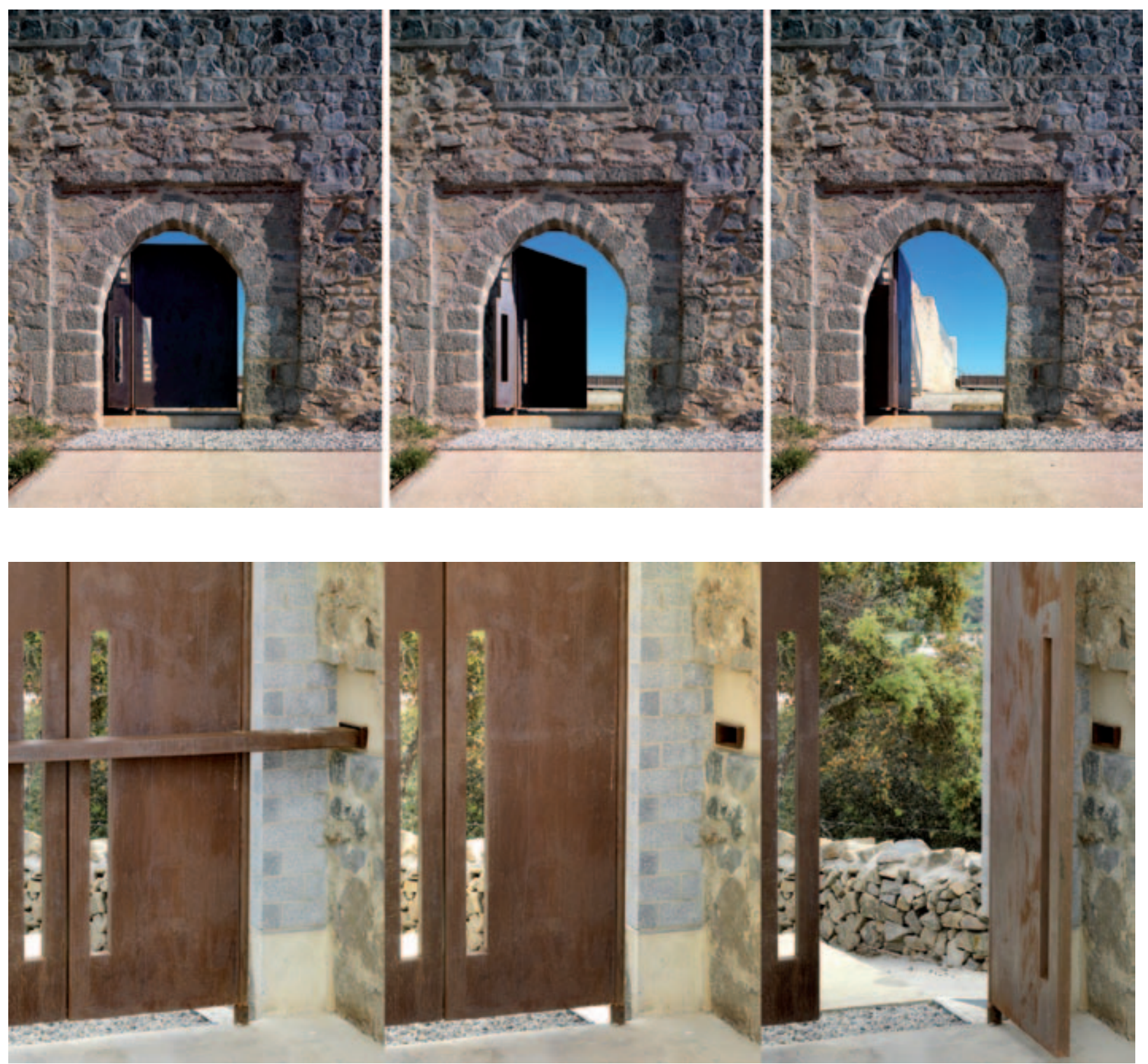

Hojas de poterna y puerta principal, en secuencia de apertura. Fotos: Jesús Granada

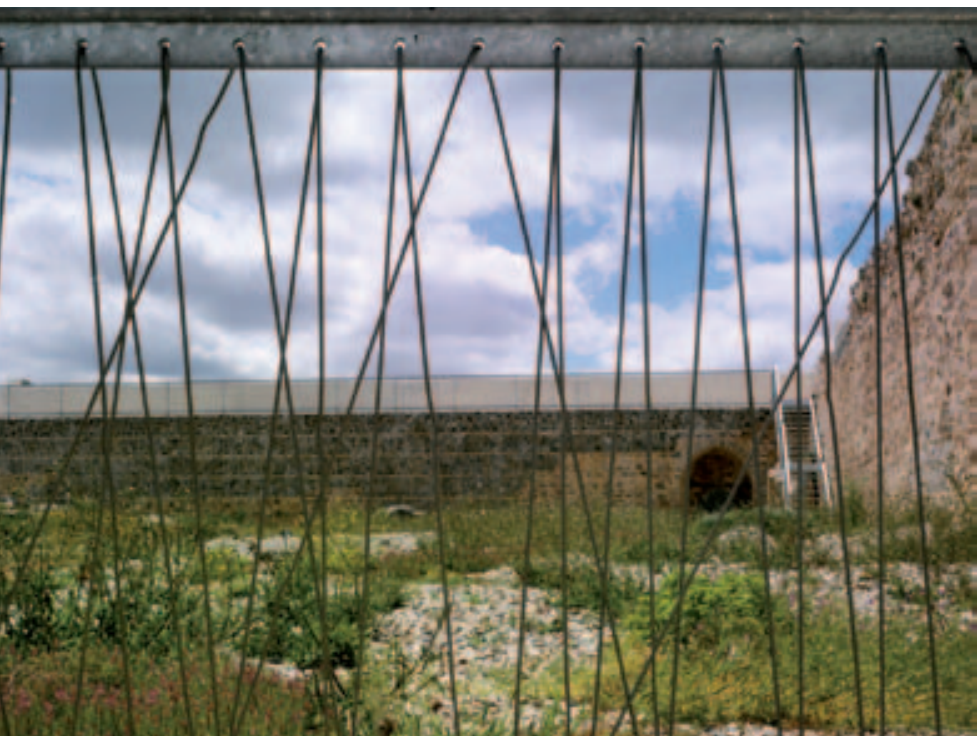

Actuaciones como ésta avalan

nuestras hipótesis -ahora

más polémicas que nunca,

en momento de cambios, de

crisis- acerca de la idoneidad de

intervenir sobre lo ya existente,

frente a la producción de

nuevos elementos edificados

Detalle elemento de protección interior, con poterna al fondo. Foło: Jesús Granada 


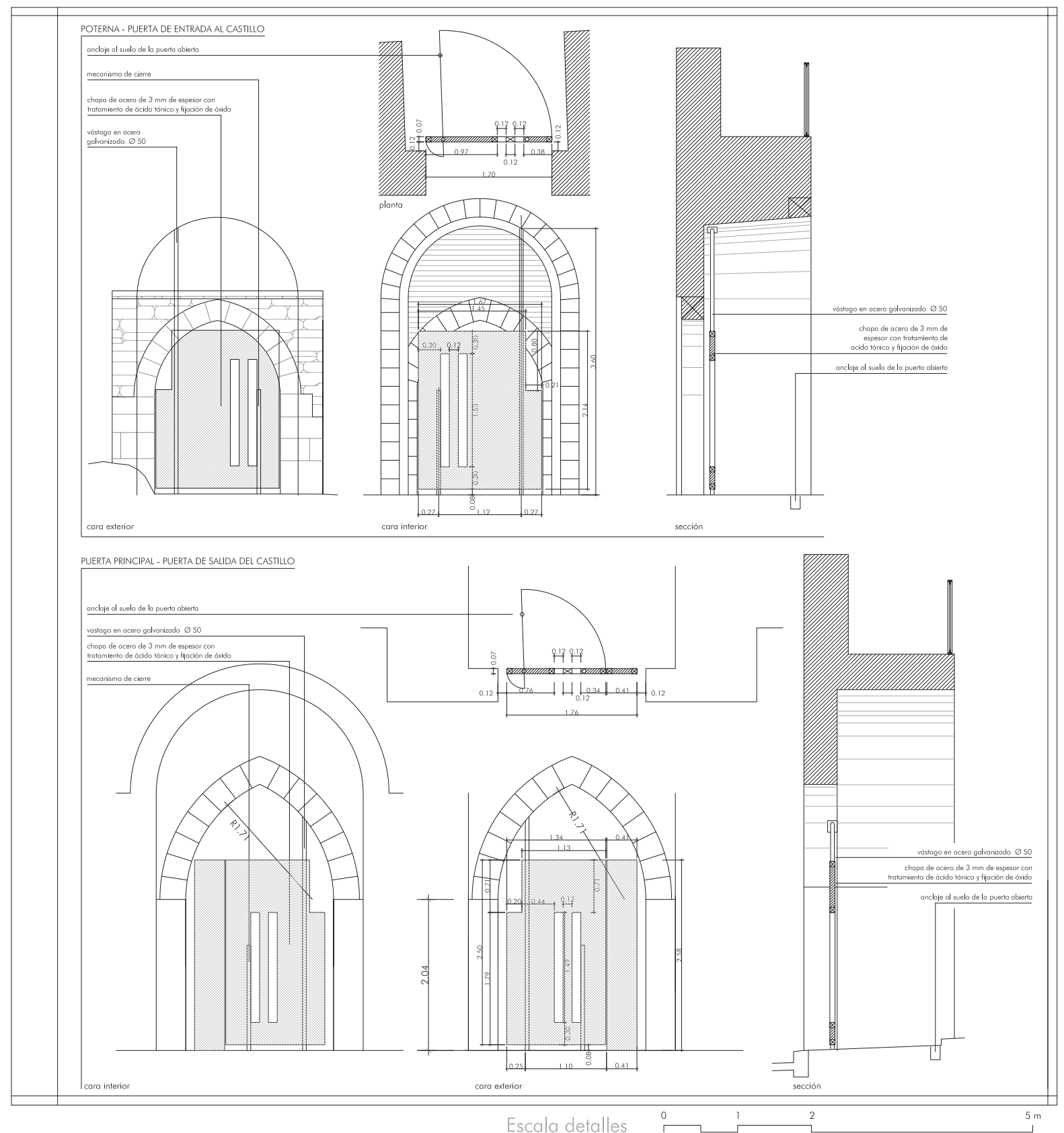

Detalles de poterna y puerta principal. Proyecto. Fuente: estudio republica_dm
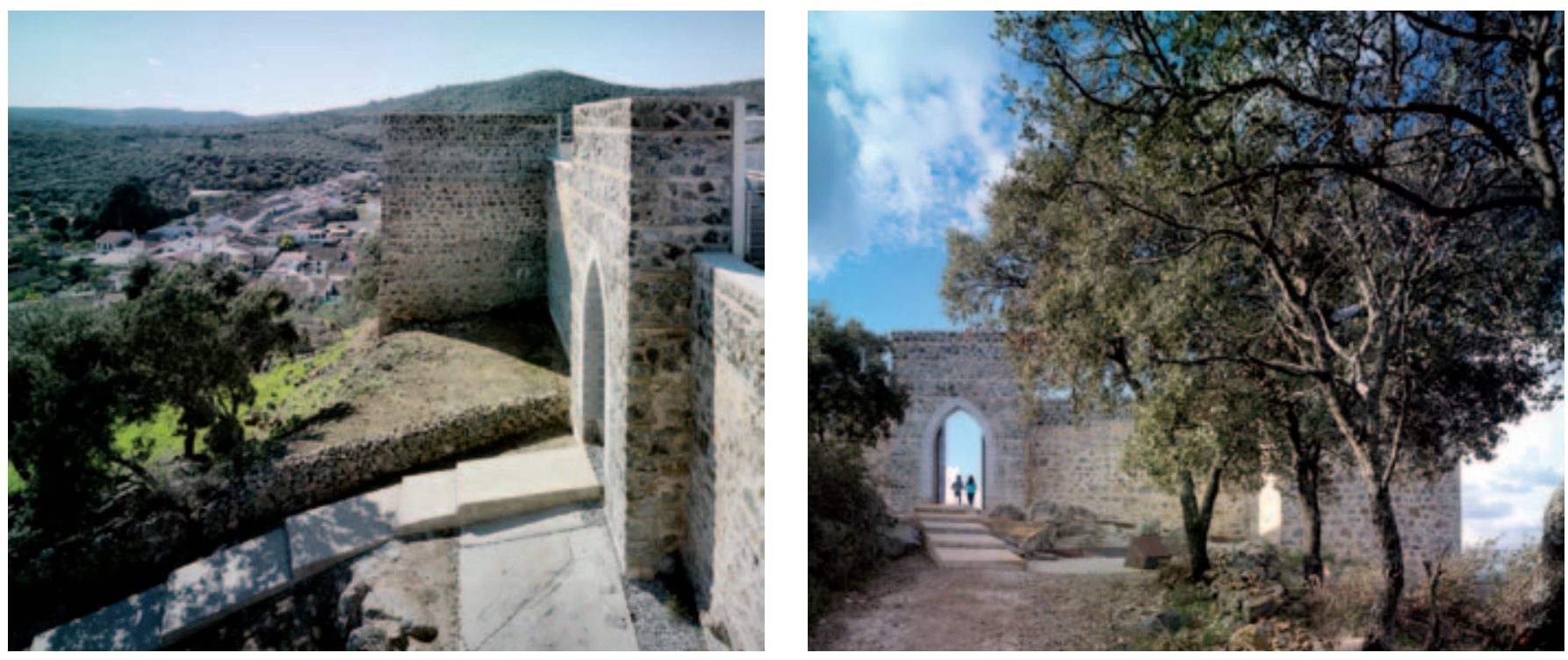

Vistas desde la puerta principal del castillo desde el exterior. Fotos: Jesús Granada 


\section{EN EL PROCESO DE OBRA...}

En el proceso de obra, con una duración aproximada de año y medio (de abril de 2010 a septiembre de 2011), resultó especialmente relevante la llegada de los materiales y maquinarias al castillo, por razones obvias de ubicación del "objeto a tratar", e igualmente el acceso al interior del patio de armas. A este respecto, resulta de justicia señalar la enorme capacidad organizativa de la contrata y la cualificación de sus técnicos y operarios, adaptados camaleónicamente a la peculiar situación. Además, la simultaneidad de los trabajos (limpieza de los lienzos, consolidación de los restos, excavación del patio de armas...) todavía complicaba más la tarea.

A nuestro entender, como directores del proceso, lo más relevante -y que no es en absoluto privativo de esta obra sino que, por el contrario, suele acaecer en la mayor parte de las actuaciones sobre el patrimonio- es el hecho de que el paso de la arquitectura de papel a la arquitectura edificada es enormemente dificultoso; máxime si estamos tratando técnicas no usuales (por innovadoras o por vernáculas casi perdidas), materiales no empleados en el siglo XXI (tales como los elementos de piedra de gran porte), etc., cuya puesta en obra exige un largo proceso de muestras a pie de oficio, y cuyo resultado no siempre está garantizado, por lo que las comprobaciones empiricas han de ser exhaustivas.

A este respecto también hemos de reconocer que, como docentes e investigadores en otros ámbitos de la práctica arquitectónica, nos parecía sugerente y necesario poner en duda ciertas decisiones del proyecto que, ahora sobre el terreno, no nos parecian idóneas o que eran susceptibles de un debate; ello ocurrió, por ejemplo, con los revestimientos continuos del envés de los parapetos del paseo de ronda, o con la definición geométrica de la puerta principal, la cual, tras la aparición de dos duelas originales, planteó serias dudas sobre su conformación originaria y, sobre todo, acerca de lo que debía ser su "traslado" a la realidad contemporánea. En este punto resultaron de especial interés las aportaciones de los compañeros Juan José Fondevilla y Rafael Usin -de la Consejería de Cultura-, Félix de la Iglesia y Juan Antonio Fernández Naranjo -de la Universidad de Sevilla-, e incluso de Danilo Lagos -desde la PUC de Santiago de Chile-.

Pero sin duda, lo que realmente ha caracterizado la presente actuación ha sido la aparición de importantes hallazgos arqueológicos que, derivados de las preceptivas campañas de seguimiento, se han obtenido. La mayor parte de los mismos han condicionado, sobre todo, las cotas finales del paseo de ronda; asi, el descubrimiento de una escalera en la coronación del lienzo oeste, o el hallazgo del firme en la torre intersección de los lienzos norte y oeste a una profundidad tal, que ha permitido el registro continuo del paseo de ronda.

También destacable, próxima a la finalización de los trabajos, la aparición de un aljibe o depósito de grano, en la torre-vigía, junto a la portada principal.
Todo lo anterior ha supuesto la necesidad de la elaboración de un Proyecto Modificado, con sus consecuentes trámites administrativos, pero con la peculiar característica relativa a los tiempos de crisis...

...ya nos encontrábamos en pleno año 2011, y los presuntos "brotes verdes" anunciados por algunos no resultaron tales.

En resumen: en ese momento no existen más fondos que los ya consignados previamente. Es decir, que cualquier cambio o mutación habrá de ser ejecutado a coste cero. Realmente es una situación inédita incluso para nosotros que, habitualmente, no permitimos desviaciones de presupuesto. Entendemos que un hallazgo arqueológico es una razón suficientemente poderosa como para suponer cierto incremento económico. Pero la situación es la que es, y no es otra; por lo tanto, es el primer documento de proyecto en nuestras vidas cuyo presupuesto final es nulo: se hubieron de repensar y mutar ciertas cuestiones (como la disminución de elementos de iluminación monumental en el interior, o la eliminación de partidas relativas a revestimientos continuos del patio de armas -en pro de los granulares- que, quizá, incluso hayan resultado favorables para la propuesta final).

\section{EPÍLOGO}

\section{Patrimonio verso sostenibilidad: la re-habilitación como estrategia de "decrecimiento"; la actuación sobre el patrimonio: re-pensamiento, re-utilización y re-generación... desde la transdisciplinariedad}

Actuaciones como ésta avalan nuestras hipótesis -ahora más polémicas que nunca, en momento de cambios, de crisis- acerca de la idoneidad de intervenir sobre lo ya existente, frente a la producción de nuevos elementos edificados.

Si hasta hace poco, lo más sostenible era no aumentar la entropía del mundo -decrecer-, sino a lo sumo, intervenir sobre el patrimonio existente -no sólo el histórico-, repensándolo, reutilizándolo, rehabilitándolo..., ahora quizá haya que complementar dicha postura, con una actitud conducente al entendimiento de la práctica arquitectónica como disciplina más social y humanistica, extrayendo de ella lo esencial, lo portátil: aquello que cupiera en una simple caja de herramientas o maletín transportable (que contendria lo imprescindible para que permitiera cargar con él y sirviera tanto para atajar situaciones límite como cotidianas).

Así, tras la aparición en escena de la multiplicidad de cuestiones que hemos relatado y que han hecho que el proceso llegara a (¿buen?) fin, se pone de manifiesto el papel de lo arquitectónico dentro de la globalidad, desde el entendimiento de que el lugar que se le destina es, sin duda, el de coordinador global, pero queriendo reflejar la transformación más desde la urdimbre transdisciplinar que desde una concepción piramidal y jerárquica. 


\section{Extracto entrevista al arqueólogo Timoteo Rivera}

¿Qué recuerdas del proceso previo, de las campañas arqueológicas, de los informes... que dieron pie y fueron el principio de la intervención en "tu" castillo, tanto en tu condición de arqueólogo como en la de nativo de Cala?

Cuando dices "mi" castillo estoy seguro de que lo haces sabiendo el especial cariño que le tengo y le he tenido a este proyecto, no sólo porque sea el castillo del pueblo donde vivo, sino también por muchas otras razones. Entre otras, que fue el primer proyecto en el que intervine como arqueólogo director, y también el primer proyecto de lo que posteriormente se ha convertido en mi principal campo de acción profesional, la así llamada arqueología de la arquitectura y el análisis paramental de edificios históricos.

Mis recuerdos de esos antecedentes son muchos, y podria retrotraerme incluso hasta unos años antes de la intervención del estudio republica_dm, cuando siendo todavía estudiante de arqueología y junto con el por entonces alcalde de Cala, empezamos a batallar en pro de la "restauración" del castillo. Desde un primer anteproyecto redactado a finales de los 90, y el enorme varapalo en la Comisión Provincial de Patrimonio, hasta la ejecución de la obra en los años 2010/11, han sido muchos los acontecimientos que se han ido sucediendo. Pero sobre todo, querría transmitir algo que me parece especialmente importante, y es que yo mismo junto con el equipo de arqueólogos que en uno u otro momento han intervenido en el castillo de Cala hemos ido progresivamente aprendiendo a hacer arqueología de la restauración en edificios históricos. Cuando se hizo la primera campaña de intervención arqueológica, la metodología de intervención sobre este tipo de inmuebles, al menos en Huelva y probablemente en toda Andalucia, estaba apenas en pañales; véanse si no como muestra las ponencias, paneles y conclusiones de las Jornadas de Arqueología Andaluza en Alcalá la Real (Jaén), de mediados de la década del 2000.

Todos nosotros procediamos de la arqueología prehistórica y, realmente, poco tiene ésta que ver con la praxis de la arqueología de la arquitectura. Mi principal recuerdo es apreciar cómo poco a poco y a medida que avanzábamos fuimos desarrollando la metodología de intervención (que posteriormente hemos ejecutado en prácticamente el resto de castillos de la banda gallega en la provincia de Huelva) y, por otro lado, cómo ibamos comprendiendo tanto el diseño inicial como la evolución constructiva del recinto. Nada tienen que ver los resultados de nuestra primera campaña de intervenciones arqueológicas, con resultados notables como fue la identificación de los huecos de ventanas amortizados en la torre del ángulo noreste, o la caracterización de las escaleras de acceso al paseo de ronda -pero con un enfoque más tradicional en arqueología-, con el informe de la segunda campaña, en el que realizamos un exhaustivo análisis paramental y de los niveles de relleno del interior del patio de armas y que, en gran medida, ha sido el punto de partida para el proyecto de intervención arquitectónica.

¿Cómo afectaron al desarrollo de la actuación los hallazgos arqueológicos realizados durante las obras? ¿modificaron tus planteamientos iniciales o los corroboraron?

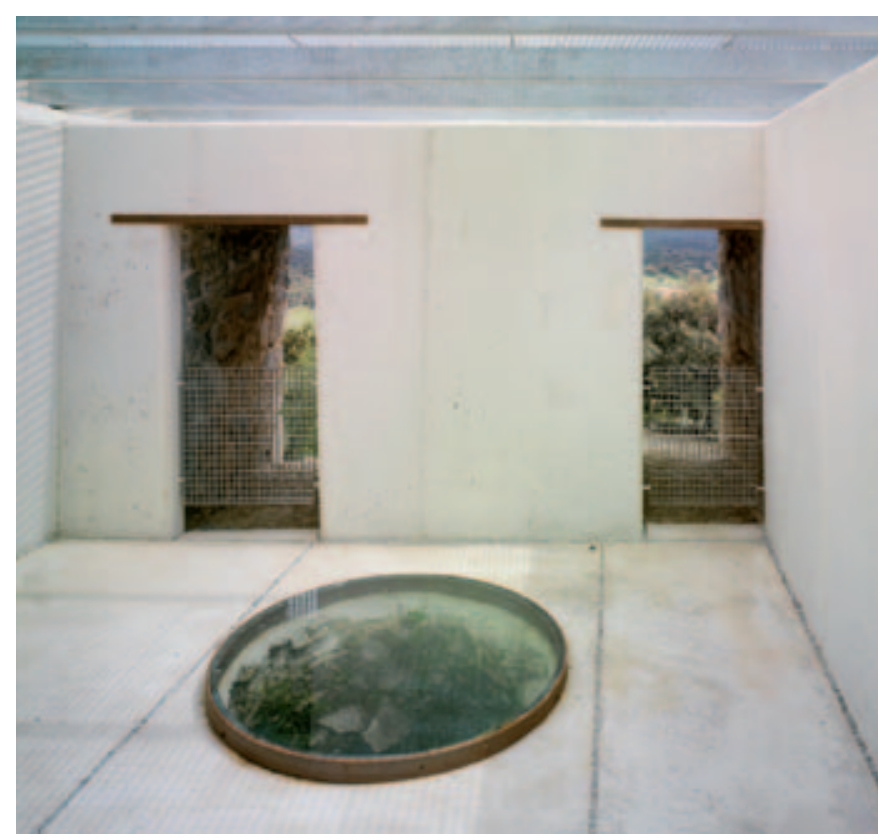

Hallazgo arqueológico de depósito y formalización de registro en torre A. Foto: Jesús Granada

Probablemente nadie era más consciente que yo, de entre todos los técnicos que hemos intervenido de una u otra manera en la obra, sobre las limitaciones de los resultados aportados desde las intervenciones arqueológicas, y de las modificaciones que al respecto podrían generarse una vez desescombrados todos los paramentos del recinto. Esperar, esperar... me esperaba algunos hallazgos. Otros, sinceramente no. Pero en conjunto tampoco han resultado tantos o, al menos, tan significativos. Es cierto que han mutado las cotas de reconstrucción del paseo de ronda en dos zonas, pero no por una incorrecta interpretación inicial, sino porque la información generada nos ha proporcionado un mayor conocimiento, y nos ha permitido la posibilidad de trabajar con niveles de dos épocas distintas, los siglos XIV y XVII, y recuperar uno u otro en función de su estado de conservación. En este sentido creo que la actuación se ha enriquecido notablemente.

Por supuesto me produjo una gran satisfacción constatar, ahora si fehacientemente, la existencia de los dos huecos de ventanas de la esquina noreste, puesta en duda a pesar de las evidencias paramentales por algunos compañeros, y también comprender a partir de los restos conservados de la torre cómo había sido la evolución constructiva de la misma, con la destrucción parcial en el siglo XVII, junto con la aparición, soterrada, del depósito existente en el suelo de la cámara... jeste sí que no me lo esperaba!

En definitiva, y desde la perspectiva de un seguimiento arqueológico de "obra de restauración", las situaciones con las que nos hemos enfrentado, en general, son las comunes, salvo excepciones. En este sentido, lo importante ha sido la flexibilidad y las ganas de hacer bien las cosas... tanto desde la arqueología como desde la arquitectura; el buen entendimiento entre todos los intervinientes, las ganas de discutir e investigar $y$, por supuesto, estar fundamentalmente de acuerdo en los criterios que debian regir la intervención (dado que el documento técnico sobre el que se apoya ésta es algo, en cierta medida, no vivo: va evolucionando a medida que evoluciona la obra y el conocimiento sobre la preexistencia patrimonial). 
Todo ello, insistimos, en el marco de una situación económica y social, de profunda crisis, que nos ha acompañado durante la consolidación formal y edilicia del monumento $y$, sin saber muy bien a ciencia cierta, qué será del castillo una vez que nos hemos ido ${ }^{7}$...

\section{Notas}

${ }^{1}$ En la RAE, preámbulo: (Del lat. praeambulus, que va delante). 1. m. Exordio, prefación, aquello que se dice antes de dar principio a lo que se trata de narrar, probar, mandar, pedir, etc. 2. m. Rodeo o digresión antes de entrar en materia o de empezar a decir claramente algo.

${ }^{2}$ Existen noticias documentales del año 1997 acerca de un encargo de rango municipal para la elaboración de un documento que se denominó Proyecto para la Reconstrucción del Castillo de Cala, con el propósito de ser elevado a la Comisión de Patrimonio de la Delegación Provincial de Huelva de la Consejería de Cultura; trámite que, según nuestro conocimiento, fue realizado, pero que dio como resultado, la desestimación de la propuesta, con carácter absoluto. Aunque, tal y como se ha indicado, dicha propuesta no tuvo trascendencia en la futura intervención arquitectónica, sin embargo pudo haber sido este episodio el que hizo que el referido organismo encargara con posterioridad los proyectos de intervención arqueológica, que debian necesariamente anteceder a la intervención arquitectónica.

${ }^{3}$ Con el número de expediente B022142CA21 HU de la Consejería de Cultura y con fecha de diciembre de 2002, aparece el primer documento elaborado por nuestro taller de arquitectura que, bajo el epígrafe de Redacción del proyecto de restauración del castillo de Cala (Huelva) y en la fase de anteproyecto, se intercala entre los dos proyectos de intervención arqueológica referidos; en el referido proyecto no se anticipan todavia las líneas de intervención en el BIC, al no disponer de la totalidad de datos necesarios respecto al mismo. Es por ello que nos resulta más oportuno comenzar la exposición de los argumentos de la intervención desde el Avance de Proyecto Básico de 2003. Ello evidencia la secuencia lógica e iterativa, de la intercalación de los trabajos consistentes en: proyectos de intervención arqueológica, tomas de datos, campañas arqueológicas, proyectos de intervención arquitectónica, campañas arqueológicas, etc. Además, incluso el avance del presupuesto del anteproyecto incorpora la partida relativa al desarrollo del programa de intervención arqueológica, poniendo una vez más en evidencia la interacción de una labor en otra y viceversa.

${ }^{4}$ Según consta en el "privilegio" de Sancho IV de 4 de septiembre de 1293, se concede a Sevilla facultad para construir los castillos de Cumbres Mayores, Santa Olalla, Aroche, Fregenal, Villanueva del Camino y Lebrija. En dicho documento aparece Cala como un lugar que debe contribuir a sufragar los gastos de construcción de los castillos de Cumbres Mayores y Santa Olalla. Esto puede significar una existencia anterior del castillo de Cala, pero también puede que se esté refiriendo a una aldea sin fortificación aún. Las primeras referencias claras del castillo aparecen en 1386, cuando se realizan obras en el mismo y constan citas respecto a ciertos libramientos, que se conservan en el Archivo Municipal de Sevilla. Otras referencias al castillo de Cala son concernientes al nombramiento de alcaides.

${ }^{5}$ Los resultados de las últimas excavaciones permitieron lanzar una hipótesis fiable de las cotas de uso interior originales, asi como estipular la "cota de relleno = cero", a partir de la cual se establecieron los criterios de la intervención. Dicho concepto resultó de especial relevancia en el proyecto arquitectónico, al poder establecer la diferencia entre el afloramiento rocoso original y el derrumbe de los lienzos junto al material de depósito a causa de la sedimentación.

${ }^{6}$ El rebaje en el patio de armas se fundamenta en los resultados obtenidos de la estratigrafía, siendo éstas las tierras que deberán ser retiradas. Por lo tanto, se podría asegurar que no serían afectados otros elementos que pudiesen existir y que aún no han sido documentadas (incluida la estratigrafía de los niveles inferiores), y que podrian tener interés desde el punto de vista arqueológico. A este respecto, señalar que, para el planteamiento general de cotas de uso del patio de armas, ha sido especialmente relevante la consideración, por parte del estudio arqueológico, de la referida "línea/cota de relleno cero", a partir de la cual se ha planteado la puesta en valor del afloramiento rocoso existente. También se ha considerado de manera prioritaria la existencia de los desagües del recinto murario para, a partir de sus cotas de uso, considerar los distintos niveles del terreno en el interior del patio de armas, y recuperar su uso primigenio.
${ }^{7}$ Desde la Alcaldia de la población, Fidel Casillas, veterinario y reciente nuevo alcalde de Cala, nos envia la siguiente nota: "El 25/09/11 el Castillo queda inaugurado, fecha a partir de la cual se genera un 'Nuevo Yacimiento de Empleo para el municipio'. Con la puesta en valor del Patrimonio Cultural, Cala cuenta con un recurso turistico potencial que puede repercutir positivamente en la economía local y por tanto en la generación de empleo. Ante esta expectativa, el Ayuntamiento de Cala estudia la posibilidad de crear un Plan Estratégico de Desarrollo Turistico en el que se incluya un sistema de gestión de dicho monumento. A día de hoy, el Ayuntamiento de Cala necesita del sustento económico de las Administraciones Públicas para el desarrollo de este proyecto ya que la solvencia económica de esta entidad es muy limitada". Se vuelve a plantear, una vez más, la problemática del uso y mantenimiento de patrimonio (una vez concluidos los larguísimos procesos de rehabilitación) en manos de entidades sin recursos... y en época de crisis.

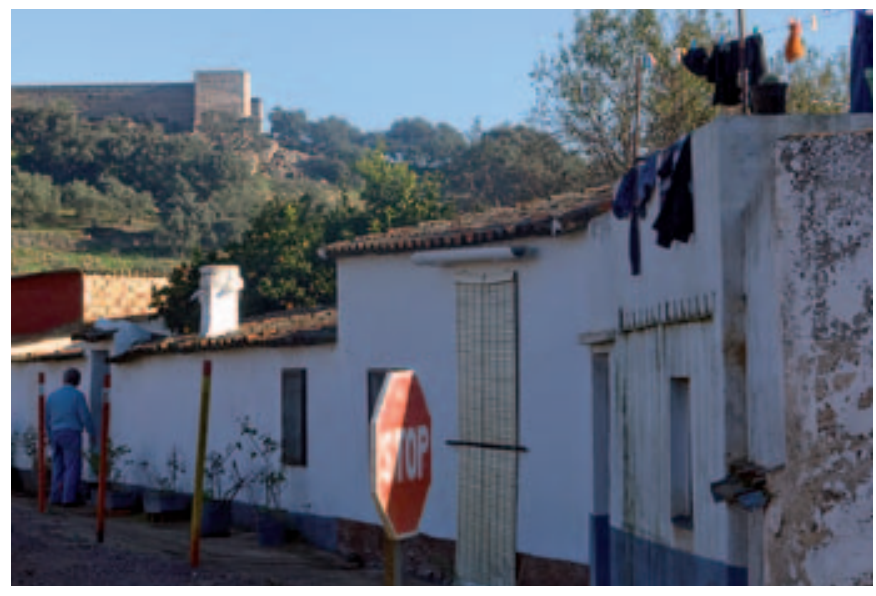

\section{FICHA TÉCNICA (VER ESQUEMA TRANSDISCIPLINAR)}

\section{Proyecto}

Intervención en el castillo de Cala (Huelva, España)

\section{Promotor}

Consejería de Cultura de la Junta de Andalucía

\section{Arquitectura}

estudio republica_dm

Rafael Herrera Limones, Carlos Parra Boyero, Victoria Rodríguez

Rodríguez, Manuel López Pradas, Juan Carlos Ruiz Galindo

Colaboradores: Fernando Díaz-Borrego Burgos, Antxón Cánovas

Arceredillo

Colaboradores fases anteriores: Rafael Herrera Castillón, Marianna

Papapietro

Colaboradores toma de datos y análisis previos: Maria Isabel Jiménez Ruiz, Marta García de Casasola Gómez

\section{Arqueología}

Timoteo Rivera Jiménez, Eduardo Romero Bomba

\section{Consultores}

Javier Gutiérrez (estructura), Estudio León (instalaciones), Pablo Olías y Jaime Hernando (maquetas), Jesús Granada y estudio republica_dm (fotografía)

\section{Constructora}

Bauen, S.A.

\section{Proyecto básico y ejecución}

Rafael Herrera Limones

\section{Dirección de obra}

Rafael Herrera Limones, Carlos Parra Boyero

\section{Dirección de ejecución}

Mariano Nieto García 


\section{Paisajes sociales: la visibilidad en la construcción de identidades}

Félix de la Iglesia Salgado, arquitecto

\section{Entornos, objetos, sujetos...}

Abandonamos la ruta de la Plata para adentrarnos en el parque natural Sierra de Aracena y Picos de Aroche por la antigua senda de los contrabandistas, voz que nos anuncia tierras de fronteras y conflictos de ida y vuelta, que nos acerca a situaciones límites. Camino a la ciudad de Cala, dejamos al paso el castillo de Santa Olalla del Cala, campanarios y cigüeñas, alineaciones de árboles que atraviesan dehesas de encinas y alcornoques, piaras de cochinos... hasta llegar a las primeras construcciones de su caserío que se pliegan al camino recibiendo al visitante. Ya en el centro, al girar la carretera a la derecha, surge en lo alto de un cerro la imagen de la fortaleza recortada entre los árboles, con su silencio elocuente y mirada pregnante.

"Y vio entonces allá arriba el castillo; vio en el aire claro su nítido contorno, más nítidamente perfilado aún por la nieve que, extendida en fina capa por doquier, reproducia todas las formas (...) En conjunto, tal y como se mostraba allá a lo lejos, respondía el castillo a la expectativa de K. No era ni un antiguo burgo feudal, ni un suntuoso palacio nuevo, sino una planta extensa..." (Franz Kafka. El Castillo)

El castillo, con una clara volumetría perfilada en su coronación con limpias líneas que lo hacen fácilmente reconocible, se incorpora con su presencia a un imaginario que nos resulta familiar. No cabe duda de que con él se establece una relación cultural, una mediación entre el ser humano y su entorno, que nos permite identificarnos con estos lugares singulares.

Al detenernos, esa relación se intensifica o hace más directa: se acrecienta la inquietud por un mayor conocimiento y comprensión de lo que esta pieza significa, al tiempo que se hace necesaria la experiencia fisica de la misma. Ahora bien, en primer lugar, es obvio que no nos relacionamos con el objeto original, no hay tal, a lo más un cuasiobjeto -recordemos a Michel Serres o Bruno Latour- móvil en el tiempo, fluctuante, híbrido; $y$, además, aquel mundo en el que el objeto como referente tenía sentido se ha descompuesto con infinidad de registros e informaciones, de impulsos y sensaciones... en mil fragmentos inimaginables e imposibles de recomponer. $Y$ ahi está y aqui estamos, conscientes de que su imagen gravita tanto sobre la vida de los caliches -o caleños- como del visitante ocasional. Para ello, entre su nada lejano estado de abandono y ruina y el momento actual, parece claro que ha sido necesario producir la intermediación entre los numerosos elementos encontrados, entre las distintas escalas de aproximación al mismo, entre el paisaje y la materialidad... lo que ha requerido de un sentido, de una propuesta patrimonial que se estableciera en guia de orientación de futuros comportamientos en el medio o en discurso vehicular de enganche al bien protegido.

En esta dimensión se sitúa el valor de la intervención que nos presenta republica_dm, una acción patrimonial rigurosa, precisa y significativa donde las categorias para su comprensión deben ser otras -las que atienden al azar o al dilatado proceso participado en el tiempo, entre otrasy las lecturas -los significados que proyecta la nueva imagen en el mundo de afuera, de la sociabilidad, del patrimonio, etc-. se singularizan y potencian. No se trata ya de hablar de lo verdadero o falso, de lo natural o artificial, de sujetos u objetos, de teoria o aplicación práctica: las dicotomias se funden en la experiencia de la nueva situación. Se trata de programar un instrumento, como nos dice Vilém Flusser en Texto e imagen (2001), "dirigido hacia el entorno para informarlo y convertirlo en cultura, en situación humana (...) Los seres humanos ya no se orientan en su entorno con la ayuda de imágenes, sino que se orientan en la imagen mediante el entorno".

\section{Los conceptos que se programaron para} hacerlo imaginable. Cuestión de miradas

Nos situamos, pues, ante su imagen, lo que -como nos ha revelado Didi-Huberman- no es otra cosa que estar ante el tiempo, "una imagen que no es ni la ilusión pura, ni toda la verdad, sino ese latido dialéctico que agita, al mismo tiempo, el velo y su jirón" (2004).

La intervención responde a un largo proceso transdisciplinar de aproximaciones y toma de decisiones colegiadas por quienes han participado en ella; algo que se traduce en un conocimiento exhaustivo de la fortaleza en la perspectiva de abrirla a nuevas interpretaciones. Referenciadas las acciones de manera explicita en los criterios marcados en la Carta de Cracovia 2000, habria que destacar la valoración arquitectónica y paisajística como patrimonio cultural, así como la participación de los ciudadanos en el proceso, lo que ha favorecido la socialización del bien y entorno.

Será la recuperación de la mirada abierta y lejana, tanto del castillo como desde el castillo, uno de los presupuestos de partida. Que la pieza recomponga su volumetria ofreciéndose a la ciudad con sus tres lienzos murarios restituidos y en la cara noreste, virtualmente, recupere el camino de ronda sobre los restos encontrados, posibilitando una intencionada mirada y valoración del paisaje de la dehesa, dan cuenta de ello. Y será en esta cara oculta, recuerdo del Promontorio del sueño de Victor Hugo, donde aparezca la sorpresa: algo se posa en la vieja ruina ahora estabilizada, un ligero animal - ¿una bicha?- a punto de saltar y abandonar, como nos diría aquella Coop Himmelblau de las primeras obras, este nuevo suelo histórico reconfigurado. Es el contraste a la "perfecta conjunción" de lo nuevo con lo viejo. Se complementa la visión.

Con otro registro distinto, a medida que nos acercamos a la obra, la disposición y superposición de planos -consolidados, recuperados, reinventados- descomponen la apariencia de aquella imagen para enfrentarse con la materialidad de la obra, con sus diferentes texturas, colores, formatos y reflejos. Ello nos conduce al tacto -ahora soporte de la mirada- y a establecer con el recinto una experiencia más directa y personal.

Así, el castillo se convierte en un dispositivo de comprensión y activación del territorio. Los itinerarios -iniciáticos- de acceso a la fortaleza son una invitación a la participación del paisaje; el recinto interior es plataforma disponible para el encuentro a la vez que valoración de su suelo natural y de la posición relativa en el cerro; los lienzos -restituidos o reinterpretados- de la muralla serán soportes de recorridos y ventanas que capturan y traen el mundo de afuera al interior en una experiencia única; su materialidad se traduce en sensaciones, en mirada y tacto; lo visible y lo que, oculto, se desvela, lo íntimo y lo externo, lo menudo y lo extenso se consideran componentes de un escenario para la vida. Algo de lo que Didi-Huberman, en Ser cráneo, ve en las esculturas y escritos de Giuseppe Penone: una arquitectura de efectos que pone en relación presencias y ausencias a través de la experiencia y que, con esos argumentos, da encarnadura a espacios olvidados, haciéndolos visibles.

Si la acción patrimonial transita del pensamiento imaginativo al conceptual y viceversa, este modelo de intervención en el castillo de Cala supone una entrada renovada en este mundo, dando cuenta de los acontecimientos de la memoria, reinventando la relación sujetoartefacto-ambiente y constituyéndose como esfera participativa y provisional.

\section{Bibliografía}

FLUSSER, V. (2001) Texto e imagen. En Una filosofia de la fotografia. Madrid: Sintesis, 2001

DIDI-HUBERMAN, G. (2004) Imágenes pese a todo. Barcelona: Paidós, 2004 